\title{
ACUTE AND CHRONIC GRAFT-VERSUS-HOST-DISEASE - A FOCUS ON PEDIATRIC PATIENTS
}

\author{
Antonio Vaz de Macedo ${ }^{1,2}$, Júlia Lopes Garcia ${ }^{3,4}$, Roseane Vasconcelos Gouveia年, Rita de Cássia \\ Barbosa Tavares ${ }^{6}$
}

1. Hematology Clinic, Hospital da Polícia Militar, Belo Horizonte, MG, Brazil.

2. Bone Marrow Transplant Unit, Hospital Luxemburgo, Instituto Mário Penna, Belo Horizonte, MG, Brazil.

3. Hematopoietic Stem Cell Transplantation Unit, Instituto de Tratamento do Câncer Infantil, Instituto da Criança, Hospital das Clínicas da Faculdade de Medicina da Universidade de São Paulo, Brazil.

4. Hematology and Bone Marrow Transplantation Unit, Hospital Israelita Albert Einstein, São Paulo, Brazil.

5. Pediatric Bone Marrow Transplant Unit, Hospital Samaritano, São Paulo, SP, Brazil.

6. Bone Marrow Transplant Center- CEMO, Instituto Nacional de Câncer, Rio de Janeiro, RJ, Brazil.

Correspondence to: antoniovmac@hotmail.com

\begin{abstract}
Graft-versus-host disease (GVHD), either in its acute or chronic form, is the main contributory factor for morbidity and non-relapse mortality after allogeneic hematopoietic stem cell transplantation (allo-HSCT). Recent advancements in the classification of this disease, with better applicability and reproducibility of standardized criteria, coupled with improvements in the management of steroid-refractory or resistant cases, have led to promising results. In 2020, the Brazilian Group for Pediatric Bone Marrow Transplantation of the Brazilian Society for Blood and Marrow Transplantation and Cellular Therapy (SBTMO) convened a task force to provide updated, evidence-based guidance for the diagnosis, classification, staging, prophylaxis, and treatment of GVHD, with a focus on the pediatric population, the results of which are presented here.
\end{abstract}

Keywords: Graft-Versus-Host Disease, Diagnosis, Classification, Grading, Staging, Prophylaxis, Treatment, Hematopoietic Stem Cell Transplantation, Pediatric, Consensus Guidelines.

\section{DEFINITION AND RISK FACTORS FOR ACUTE AND CHRONIC GRAFT-VERSUS-HOST DISEASE}

The original classification of acute graft-versus-host disease (GVHD) was published in 1974 and was based on time of onset as the sole criterion. From 2005 onwards, patients presenting with typical acute GVHD (aGVHD) symptoms before $D+100$ were categorized as having "classical aGVHD", whereas those with such manifestations starting after D+100 were classified as having "late onset or recurrent aGVHD".

In 2005, the National Institutes of Health (NIH) published a new set of consensus guidelines harboring both the diagnostic and the grading criteria for chronic GVHD (cGVHD), including various aspects pertaining to the diagnosis, classification, and treatment of this post-hematopoietic stem cell transplant (HSCT) complication ${ }^{1,2}$.
Roughly a decade later, in 2014, the NIH updated these guidelines, which kept the original structure, but added more robust evidence-based guidance for the diagnosis and management of $\mathrm{CGVHD}^{3}$. These guidelines focused on controversial aspects, including, but not limited to, the distinction between active disease and prior tissue injury. Additionally, the diagnostic criteria for target-organ involvement, such as mouth, eyes, genitalia, and lungs, were thoroughly revised, and CGVHD-related organ impairment was specifically addressed. In short, this update aimed at a comprehensive diagnostic and prognostic assessment of cGVHD, as well as at better guidance toward appropriate treatment and defining eligibility for clinical trials, with greater specificity and precision. ${ }^{3}$.

A number of risk factors have been widely recognized as related to an increased incidence of 
aGVHD ${ }^{4,5,6}$. These factors may be directly related to the recipient, the donor, the graft, or the HSCT itself. Age, baseline disease, sex (particularly female donor to male recipient combinations), Human Leukocyte Antigen (HLA) mismatch, conditioning regimen intensity, GVHD prophylaxis used, stem cell source (peripheral blood $>$ bone marrow $>$ umbilical cord blood), CD34+ count, T-lymphocyte depletion, and infection risk are among the main risk factors in this regard.

During the last few years, several biomarkers have been investigated as potential surrogates for a greater occurrence of aGVHD or a worse response to therapy $^{7}$. In this respect, a panel of four biomarkers has been more widely investigated: suppressor of tumorigenesis 2 (ST2), regenerating islet-derived 3-alpha (REG3a), tumor necrosis factor (TNF) alpha receptor type 1(TNFR1a) and interleukin-2 receptor alpha (IL$2 \mathrm{Ra}$ orCD25) ${ }^{7}$. ST2, for instance, has been shown to be an important biomarker of treatment-resistant $\mathrm{aGVHD}^{7}$. Nonetheless, these biomarkers are not yet available for use in clinical practice in Brazil.

The Endothelial Activation and Stress Index (EASIX) serves as a practical tool for identifying patients with high-risk GVHD, since it is based on readily available laboratory markers, namely: lactate dehydrogenase $(\mathrm{LDH})$, serum creatinine, and platelet count ${ }^{8}$. The EASIX score may be useful for identifying patients, including children, with aGVHD who are at greater risk of death, particularly in the reduced-intensity conditioning (RIC) setting, where a statistically significant difference was shown ${ }^{8}$. The EASIX score may thus become an important clinical tool for the development of a risk-adapted strategy toward the treatment of GVHD.

As for CGVHD, the main underlying risk factor is a prior history of aGVHD.

\section{ACUTE GVHD DIAGNOSIS AND CLINICAL DESCRIPTION}

Acute GVHD is a reaction of donor immune cells against host tissues which can occur after allogeneic HSCT (allo-HSCT). The three main tissues affected by acute GVHD are skin, liver, and gastrointestinal (Gl) tract. Its onset normally correlates with engraftment of donor cells.

Acute GVHD is commonly suspected based on the clinical presentation that represents the organs involved. The earliest and most common manifestation is skin GVHD. This is essentially a maculopapular rash that can begin anywhere in the body but often starts in palm and sole, with or without pruritus or tenderness in affected areas. If the rash progresses, it may become confluent. In severe cases, blisters may occur. The GI manifestations include diarrhea, which may become bloody, cramping, nausea, and vomiting. Furthermore, jaundice from hyperbilirubinemia is the hallmark of liver $\mathrm{GVHD}^{9}$, although a hepatitic variant of GVHD with elevated liver enzymes, as in an acute viral hepatitis, has been recognized ${ }^{10}$ ).

The diagnosis of aGVHD is a clinical one but, as many of the symptoms of aGVHD are non-specific, histologic confirmation, whenever possible, may be extremely useful. Tissue biopsy is recommended to confirm a histological diagnosis of aGVHD and, most importantly, to exclude opportunistic infection or drug toxicity. However, the combination of rash, nausea, and diarrhea, occurring after neutrophil engraftment renders the diagnosis very likely. The histologic hallmark of cellular injury by GVHD is apoptosis, which is observed in basal epidermal keratinocytes, bile ducts, and/or intestinal crypt epithelial cells and is frequently associated with lymphocyte infiltration ${ }^{11}$.

\section{GRADING OF AGVHD}

As mentioned above, the skin, Gl tract and liver are the main target organs affected in aGVHD. The first organ affected is most often the skin, which is clinically manifested as a maculopapular rash in the nape, cheeks, ears, shoulder (head end), palms and soles. It can disseminate throughout the body surface (BS) and become confluent and, sometimes, itchy. In severe forms, bullous wounds secondary to epidermal necrosis occur. The degree of cutaneous involvement is quantified by the extent and severity of lesions, as described in tables 1 and 2.

Regarding the Gl tract, it often affects both its upper and lower portions. It may clinically present with anorexia, nausea, vomiting, diarrhea, and abdominal pain. The diagnosis can be confirmed by histopathological examination of biopsies obtained through upper digestive tract endoscopy, rectal biopsy or, in some cases, colonoscopy, depending on the risk of bleeding. Several studies, including a recent prospective one, suggest that most GI tract GVHD diagnoses can be made through rectal biopsies ${ }^{12}$.

It is important to note that a negative rectal biopsy does not rule out aGVHD, for which further endoscopy is required to confirm the diagnosis and differentiate it from other common pathologies, mainly infections, of the early post-HSCT period.

The degree of Gl tract involvement is classified by the severity of the diarrhea, as described in tables 1 and 2 . 
GVHD of the lower Gl tract is usually severe, with or without hematochezia and abdominal cramps. The diarrhea is often watery and abundant (up to several liters per day) and may become bloody. In such cases, it is of utmost importance that blood transfusion support is assured, along with hydroelectrolytic replacement, use of opiates to control pain, and close monitoring due to the risk of hemodynamic instability.

As diarrhea is a common presentation in the immediate post-HSCT period and can be caused by organic toxicity due to the conditioning regimen or by broad-spectrum antibiotics, histopathological examination may serve as a useful diagnostic tool to exclude bacterial toxins or concomitant cytomegalovirus (CMV) infection.

GVHD of the upper Gl tract must also be differentiated from herpes simplex virus infection, candida esophagitis, peptic ulcer, and secondary toxicity, which can be achieved by endoscopy.

The liver injury caused by GVHD generally occurs in patients with concurrent signs of skin and / or Gl tract GVHD and is only rarely seen in its isolated form. It often presents itself with abnormal liver function tests, with a characteristic rise in total bilirubin (predominantly in its conjugated form) and alkaline phosphatase. It can progress to painful hepatomegaly, fluid retention, and pruritus. In a few cases, coagulopathy may be present.

These laboratory abnormalities reflect biliary canaliculi destruction, leading to cholestasis. However, these changes are non-specific and should be differentiated from those of other disorders, such as sinusoidal obstruction syndrome (SOS), viral hepatitis, and drug toxicities (from conditioning, antimicrobial therapy, or GVHD prophylaxis). Liver biopsy may play an important role in the diagnosis, but it is generally not feasible due to the high risk of bleeding.

The graduation of hepatic GVHD is based on bilirubin serum levels and is also summarized in tables 1 and 2 , below.

The most popular systems for graduating GVHD are those of Glucksberg (grades I-IV) and the International Bone Marrow Transplant Registry (IBMTR)(A-D) ${ }^{13,14}$. The severity of aGVHD is determined by assessment of the degree and extent of each organ involved, as summarized in tables 1 and 2 . The stages of individual organ involvement are combined using the Glucksberg with or without the IBMTR criteria. Grade I(A) aGVHD is characterized as mild disease, grade II(B) as moderate, grade III(C) as severe, and grade IV(D), as life-threatening ${ }^{14,15}$.) The IBMTR grading system defines the severity of aGVHD as follows (adapted for children from Rowlings PA, 1997 and Carpenter PA, 2010) ${ }^{13,11,16 \text { : }}$

- Grade A - Stage 1 skin involvement alone (rash of $<25 \%$ of BSA with no liver or Gl involvement);

- Grade B - Stage 2 skin involvement; Stage 1 to 2 gut or liver involvement (rash of $25-50 \%$ of BSA; diarrhea $10-19.9 \mathrm{ml} / \mathrm{kg} /$ day - stage 1 ; diarrhea $20-30 \mathrm{ml} / \mathrm{kg} /$ day - stage 2; bilirubin 2.1 to $3.0 \mathrm{mg} /$ $\mathrm{dL}$ - stage 1 ; bilirubin 3.1 to $6.0 \mathrm{mg} / \mathrm{dL}$ - stage 2 );

- Grade C - Stage 3 involvement of any organ system (generalized erythroderma; bilirubin 6.1 to $15.0 \mathrm{mg} / \mathrm{dL}$; diarrhea $>30 \mathrm{ml} / \mathrm{kg} /$ day);

- Grade D - Stage 4 involvement of any organ system (generalized erythroderma with bullous formation; bilirubin $>15 \mathrm{mg} / \mathrm{dL}$; frank blood or melena or pain or ileus).

TABLE 1: Grading of Acute Graft-Versus-Host Disease

Glucksberg Grade

I - Stage 1 or 2 skin involvement; no liver or gut involvement; Lansky PS 90-100

II - Stage 1 to 3 skin involvement; Stage 1 liver or gut involvement; Lansky PS 70-80

III - Stage 2 or 3 skin, liver, or gut involvement; Lansky PS 50-60

IV - Stage 1 to 4 skin involvement; Stage 2 to 4 liver or gut involvement; Lansky PS 30-40

International Bone Marrow Transplant Registry Severity Index

A - Stage 1 skin involvement; no liver or gut involvement

B - Stage 2 skin involvement; Stage 1 to 2 gut or liver involvement

C - Stage 3 skin, liver, or gut involvement

D - Stage 4 skin, liver, or gut involvement 
TABLE 2: MAGIC target organ acute GVHD staging in children

\begin{tabular}{|c|c|c|c|c|}
\hline Stage & Skin (erythema) & $\begin{array}{c}\text { Liver } \\
\text { (bilirubin) }\end{array}$ & Upper GI tract & Lower GI tract (stool output per day) \\
\hline 0 & No active rash & $<2 \mathrm{mg} / \mathrm{dL}$ & $\begin{array}{l}\text { No or intermittent } \\
\text { nauseaa, vomiting, } \\
\text { anorexia }\end{array}$ & $<10 \mathrm{ml} / \mathrm{kg} /$ day or $<4$ episodes/dayb \\
\hline 1 & $\begin{array}{l}\text { Maculopapular rash } \\
<25 \% \text { BSA }\end{array}$ & $2-3 \mathrm{mg} / \mathrm{dL}$ & $\begin{array}{c}\text { Persistent nausea, } \\
\text { vomiting or anorexiaa }\end{array}$ & $10-19.9 \mathrm{ml} / \mathrm{kg} /$ day or $4-6$ episodes/day \\
\hline 2 & $\begin{array}{l}\text { Maculopapular rash } \\
25-50 \% \text { BSA }\end{array}$ & $3.1-6 \mathrm{mg} / \mathrm{dL}$ & & $20-30 \mathrm{ml} / \mathrm{kg} /$ day or $7-10$ episodes/day \\
\hline 3 & $\begin{array}{c}\text { Maculopapular rash } \\
>50 \% \text { BSA }\end{array}$ & $6.1-15 \mathrm{mg} / \mathrm{dL}$ & & $>30 \mathrm{ml} / \mathrm{kg} /$ day or $>10$ episodes/day \\
\hline 4 & $\begin{array}{c}\text { Generalized } \\
\text { erythroderma ( }>50 \% \\
\text { BSA) plus bullous } \\
\text { formation and } \\
\text { desquamation }>5 \% \\
\text { BSA }\end{array}$ & $>15 \mathrm{mg} / \mathrm{dL}$ & & $\begin{array}{c}\text { Severe abdominal pain with or without } \\
\text { ileus, or grossly bloody stool (regardless } \\
\text { of stool volume). }\end{array}$ \\
\hline
\end{tabular}

Legend: a. Acute GVHD is suspected if anorexia is associated with weight loss, nausea $\geq 3$ days, and/or vomiting $\geq 2$ episodes/day for at least 2 days; b. one episode of diarrhea corresponds to approximately $3 \mathrm{ml} / \mathrm{kg}$ of stool volume in children $(<50 \mathrm{~kg})$. If $>50 \mathrm{~kg}$, consider an approximate stool volume of $200 \mathrm{ml}$ as in adults.

MAGIC: Mount Sinai Acute GVHD International Consortium; GI: gastrointestinal tract; BSA: body surface area. Adapted from Harris AC, $2016^{16}$.

\section{PROPHYLAXIS AND BIOMARKERS OF GVHD IN PEDIATRIC PATIENTS}

Allo-HSCT practices in children differ from those applied to adults mainly because of the following factors inherent in the pediatric population: lower incidence of acute and chronic GVHD, differences in transplant baseline variables (non-malignant diseases, comorbidities, previous treatments, graft sources) and better thymic function. Since HSCT can treat a wide range of non-malignant diseases in children and GVHD is usually less severe and responds better to treatment in this population, GVHD prophylaxis strategies vary more between pediatric than adult transplant centers, particularly among recipients with malignant diseases ${ }^{17}$.

Although several pediatric studies were (or are being) conducted to test new strategies, such as ultralow-dose IL- ${ }^{18}$, sirolimus ${ }^{19-21}$, maraviroc ${ }^{22}$, individualized mycophenolate mofetil (MMF) ${ }^{23}$ and anti-thymocyte globulin (ATG) dosing ${ }^{24-25}$, abatacept ${ }^{26}$, ex-vivo T-cell depletion (CD34 positive selection and/ or T-cell subset depletion) ${ }^{27-29}$, calcineurin inhibitors
(CNI) remain the standard for GVHD prophylaxis in adults and children $^{30}$. Few yet important options have been consolidated in the past decade, the most important of which are: cyclosporine A (CsA) as a single agent for matched sibling donor (MSD) transplants ${ }^{31}$ or with rabbit ATG (rATG) for matched unrelated donor (MUD) ${ }^{32}$ ones as safe options for children under 12 years old ${ }^{33}$; and post-transplantation cyclophosphamide (PTCy) ${ }^{34-36}$ or alpha-beta+ T-cell receptor (TCR) and CD19+ depletion for mismatched related or unrelated donor (haploidentical or MMUD) $\mathrm{HSCT}^{37-38}$.

Lawitschka and cols..$^{39}$ performed a survey capturing different real-life approaches for pediatric GVHD prophylaxis. Single-agent CsA was used for MSD myeloablative HSCT in $47 \%$ of the 75 included EBMT centers; most of them used a dose of $1.5 \mathrm{mg} /$ $\mathrm{kg}$ twice a day and reported lower CsA blood levels (100-150ng/ml in $37 \%$ and $160-200 \mathrm{ng} / \mathrm{ml}$ in $34 \%$ ). According to the conditioning regimen, CsA target levels $<200 \mathrm{ng} / \mathrm{ml}$ were reported for myeloablative conditioning (MAC) by $85 \%$ and for RIC by $68 \%$ of the responding centers, without a higher target lev- 
el during the first weeks. The relapse risk in malignant diseases induced early CsA withdrawal, whereas longer CsA maintenance and higher target levels (> $200 \mathrm{ng} / \mathrm{ml}$ ) was the policy for non-malignant diseases. Most centers (95\%) used CsA with methotrexate (MTX), and $81 \%$ used additional ATG for MUD and $96 \%$ for mismatched donor (MMD) transplants, while only $21 \%$ used this approach for MSD HSCT. Scheduling of MTX and leucovorin rescue varied as follows: $10 \mathrm{mg} / \mathrm{m}^{2}$ (days $+1,+3$ and +6 ) in $37 \%, 15$ $\mathrm{mg} / \mathrm{m}^{2}($ day +1$)+10 \mathrm{mg} / \mathrm{m}^{2}$ (days $+3,+6$ and +11$)$ in $28 \%$, and $25 \%$ of the centers used the latter option omitting the day +11 dose. Ex-vivo T-cell depletion was used by 50 centers (positive CD34+ selection in $78 \%$ and negative selection in $44 \%$ ), usually for MMD transplants. Prophylaxis for RIC HSCT, mainly for non-malignant diseases, varied widely; the combination of CSA and MTX was the most frequently used regimen (92\%), and 90\% used additional ATG. Other agents, such as tacrolimus, MMF and alemtuzumab, were used by $19 \%, 43 \%$ and $23 \%$ of the centers, respectively, for aGVHD prophylaxis.

In Brazil, three recent retrospective multicenter studies performed by the Brazil-Seattle GEDECO Consortium evaluating outcomes in pediatric HSCT patients observed a low incidence of severe acute and cGVHD. Darrigo Jr and cols. ${ }^{40}$ reported an incidence of $11 \%$ of grade III-IV aGVHD and of $19 \%$ of cGVHD in 37 patients treated with bone marrow transplantation from a MUD for severe aplastic anemia (SAA). GVHD prophylaxis comprised CsA and MTX in 97\% plus in-vivo T-depletion in $100 \%$ of cases. Tavares and cols $^{41}$, in turn, showed incidences of grade III-IV aGVHD of $18 \%, 13 \%$ and $17 \%$ and of moderate/severe cGVHD of $8 \%, 22 \%$ and $4 \%$ after MUD $(n=95)$, MMUD ( $n=47)$ and umbilical cord blood (UCB) $(n=$ 70) transplants, respectively, in patients undergoing HSCT for acute leukemia and myelodysplastic syndrome. In this study, GVHD prophylaxis consisted of a calcineurin inhibitor (CNI) + MMF or steroids in $90 \%$ of UCB transplants and of a CNI + MTX in $80 \%$ and $89 \%$ of MUD and MMUD transplants, respectively. ATG was used in $57 \%$ of UCB, $66 \%$ of MUD, and $83 \%$ of MMUD recipients. In their haploidentical HSCT study, Fernandes and cols $^{42}$ reported incidences of $14 \%$ and $16 \%$ of grade III-IV acute and chronic GVHD, respectively, in 73 patients with primary immunodeficiency diseases. These patients received PTCy, MMF and a CNI as GVHD prophylaxis, coupled with ATG or alemtuzumab in half of the patients.

As an effective and widely available strategy, PTCy induces functional impairment of alloreactive T-cells supported by highly active suppressive mechanisms, including rapid preferential recovery of regulatory $T$ cells (Tregs), thus preventing donor cells from causing GVHD. Haploidentical HSCT with PTCy has been associated with low rates of GVHD and non-relapse mortality (NRM). Efficacy and overall survival (OS) seem comparable to MUD transplants in a number of published studies, though more robust head-tohead comparisons are still underway. Delayed immune reconstitution after PTCy has been shown to lead to a higher incidence of infectious complications, including CMV infection. Furthermore, decreasing relapse in malignant and graft failure in non-malignant diseases without additional toxicity remains an important challenge. GVHD prophylaxis in this setting consist of PTCY $(50 \mathrm{mg} / \mathrm{kg}$ on days +3 and +4 ) plus tacrolimus or CsA (target levels between 5 to 15 $\mathrm{ng} / \mathrm{mL}$ and 200 to $400 \mathrm{ng} / \mathrm{mL}$, respectively) and MMF ( 30 to $45 \mathrm{mg} / \mathrm{kg}$ divided in 3 daily doses), both from day +5 , until 1 year and day +35 post-HSCT, respectively. The addition of rATG $(0.5 \mathrm{mg} / \mathrm{kg}$ on day -9 and $2 \mathrm{mg} / \mathrm{kg} /$ day on days -8 and -7 ) may be necessary to overcome engraftment failure in non-malignant diseases, particularly in immunosuppression-naive SAA patients ${ }^{43}$.

Prophylactic in vivo T-cell depletion with ATG has been associated with decreased GVHD rates in many allo-HSCT settings. Walker and cols. ${ }^{44}$ tested the benefit of adding rATG to standard GVHD prophylaxis in a recent randomized, multicenter, phase 3 trial. Included patients (196) had a hematologic malignancy (leukemia, myelodysplastic syndrome, or lymphoma), were between 16 and 70 years of age, and received a MUD or a one-locus mismatched graft at HLA-A, HLA-B, HLA-C, or DRB1 following MAC or RIC. In patients receiving $\mathrm{rATG}(0.5 \mathrm{mg} / \mathrm{kg}$ on day -2 , and $2 \mathrm{mg} / \mathrm{kg}$ on days -1 and +1 ) plus $\mathrm{CNI}+$ MTX or MMF, they observed a significant improvement in the incidence of CGVHD (26.3\%) as compared to that of the standard GVHD prophylaxis group(41.3\%), $p=0.032$, and in the OS rate (70.6\% vs. $53.3 \%)$; adjusted hazard ratio (HR) 0.56 (95\% Confidence Interval - Cl: 0.35$0.90, p=0.017$ ) at 24 months. Moreover, cGVHD-free, relapse-free survival (GRFS) at 12 months was $57.6 \%$ in the rATG combined group vs. $40.2 \%$ in the standard GVHD prophylaxis group $(p=0.010)$. Despite decades of clinical study, optimal ATG dosing is yet to be determined. Increasing evidence shows that the current weight-based dosing is suboptimal and that the absolute lymphocyte count (ALC) before the first dose of rATG can determine its clearance and thus drug exposure. Depending on the conditioning regimen (mainly total body irradiation $v s$. busulfan-based conditioning), the ALC before rATG was highly variable. Adult patients with low ALCs 
had worse OS compared with those with a higher ALC when receiving rATG. Currently, a historically controlled clinical trial in children (the PARACHUTE study; NTR4960) investigating a fully personalized dosing regimen for rATG is at the analysis stage. The proposed dosing regimen varied from $2 \mathrm{mg} / \mathrm{kg}$ to 10 $\mathrm{mg} / \mathrm{kg}$, depending on body weight and ALC, starting 9 days before HSCT. A preliminary analysis has indicated an apparent improvement in survival and that early CD4+ T-cell recovery is significantly faster and more robust with individualized dosing ${ }^{45}$.

Table 3 summarizes the recommendations for GVHD prophylaxis for MAC, non-myeloablative (NMA), and RIC allo-HSCT in pediatric patients, including peripheral blood stem cell (PBSC) and haploidentical transplants, along with their corresponding levels of evidence and grades of recommendation.

TABLE 3- Recommendations for graft-versus-host disease prophylaxis in pediatric patients

\begin{tabular}{|c|c|c|c|}
\hline Type of HSCT & Disease/ Graft Source & Prophylaxis Regimen & $\begin{array}{l}\text { Level of } \\
\text { Evidence }\end{array}$ \\
\hline \multirow{4}{*}{$\begin{array}{l}\text { MAC allo-HSCT from HLA- } \\
\text { matched related donors }\end{array}$} & . Malignant - BM & $\mathrm{CNI} \pm$ short MTX $10 \mathrm{mg} / \mathrm{m} 2(\mathrm{D}+1,3,6)^{*}$ & $1 \mathrm{~b}, \mathrm{GR}-\mathrm{A}$ \\
\hline & . Malignant - PB & $\mathrm{CNI}+$ short MTX \pm rATG & $2 b, G R-B$ \\
\hline & $\begin{array}{l}\text { Non-malignant } \\
\text { (BM or PB) }\end{array}$ & $\begin{array}{c}\mathrm{CNI}+\mathrm{MTX} \text { standard }-15 \mathrm{mg} / \mathrm{m} 2 \mathrm{D}+1 \text { and } 10 \mathrm{mg} / \\
\mathrm{m} 2(\mathrm{D}+3,6,11)\end{array}$ & 1a, GR- A \\
\hline & & (if PB, rATG $2,5-5 \mathrm{mg} / \mathrm{kg}$ can be added) & $2 b, G R-B$ \\
\hline \multirow{4}{*}{$\begin{array}{l}\text { MAC allo-HSCT from HLA- } \\
\text { matched or } 9 / 10 \text { unrelated } \\
\text { donors }\end{array}$} & . Malignant - BM & $\mathrm{CNI}+\mathrm{rATG}(4.5 \mathrm{mg} / \mathrm{kg}) \pm$ short MTX* & $2 b, G R-B$ \\
\hline & . Malignant - PB & $\mathrm{CNI}+\mathrm{rATG}(<6 \mathrm{mg} / \mathrm{kg})+$ short MTX & $2 b, G R-B$ \\
\hline & $\begin{array}{l}\text { Non-malignant (BM } \\
\text { or PB) }\end{array}$ & $\mathrm{CNI}+\mathrm{rATG}(<6 \mathrm{mg} / \mathrm{kg})+\mathrm{MTX}$ standard & $1 \mathrm{a}, \mathrm{GR}-\mathrm{A}$ \\
\hline & & (if UCB: CNI + rATG + MMF) & $2 b, G R-B$ \\
\hline $\begin{array}{l}\text { MAC allo-HSCT from } \\
\text { related or unrelated donors }\end{array}$ & $\begin{array}{l}\text { Malignant or non- } \\
\text { malignant } \\
(\mathrm{BM}, \text { avoid PB) }\end{array}$ & $\begin{array}{c}\text { HD PTCy }(50 \mathrm{mg} / \mathrm{kg} / \text { day on } \mathrm{D}+3, \mathrm{D}+4) \\
\text { If PB, unrelated, or mismatched donors: add CNI } \\
+ \text { MMF or MTX }\end{array}$ & $2 b, G R-C$ \\
\hline $\begin{array}{l}\text { RIC or NMA allo-HSCT from } \\
\text { related or unrelated donors }\end{array}$ & $\begin{array}{l}\text { Malignant or non- } \\
\text { malignant } \\
\text { (BM or PB) }\end{array}$ & $\begin{array}{l}\mathrm{CNI}+\mathrm{MTX} \text { (as for MAC) or MMF ( } 15 \mathrm{mg} / \mathrm{kg} \text { in } 3 \\
\text { daily doses) } \pm \text { rATG }(4-6 \mathrm{mg} / \mathrm{kg} \text { ) if PB or unrelated }\end{array}$ & $2 b, G R-C$ \\
\hline \multirow{2}{*}{$\begin{array}{l}\text { Haploidentical } \\
\text { allo-HSCT - Baltimore } \\
\text { regimen }\end{array}$} & . Malignant & $\begin{array}{c}\text { HD PTCy }(50 \mathrm{mg} / \mathrm{kg} / \text { day on } \mathrm{D}+3, \mathrm{D}+4) \text { plus CNI + } \\
\text { MMF }\end{array}$ & $2 b, G R-B$ \\
\hline & $\begin{array}{l}\text { Non-malignant (avoid } \\
\text { PB or mother as donor) }\end{array}$ & $\begin{array}{c}\text { Same as above }+ \text { rATG }(0.5 \mathrm{mg} / \mathrm{kg} \text { on } \mathrm{D}-9,2 \mathrm{mg} / \mathrm{kg} / \\
\text { day on } \mathrm{D}-8, \mathrm{D}-7)\end{array}$ & $3 b, G R-C$ \\
\hline
\end{tabular}

HSCT: hematopoietic stem cell transplantation; allo-HSCT: allogeneic HSCT; MAC: myeloablative conditioning; RIC: reduced-intensity conditioning; NMA: non-myeloablative conditioning; HLA: human leukocyte antigen; BM: bone marrow; PB: peripheral blood; UCB: umbilical cord blood; CNI: calcineurin inhibitor (cyclosporine or tacrolimus); MTX: methotrexate; GR: grade of recommendation; r-ATG: rabbit anti-thymocyte globulin; MMF: mycophenolate mofetil; HD PTCy: high dose post-transplant-cyclophosphamide. ${ }^{*} \mathrm{CNI}$ alone or with MTX can be the choice in children < 12 years old after bone marrow transplantation for malignant diseases from HLA-matched donors; $\bowtie$ Since UCB transplantation is rarely used nowadays, the dose and use of rATG should be determined on a case-by-case basis, and mini-MTX can possibly replace MMF. 


\section{BIOMARKERS FOR ACUTE AND CHRONIC GVHD}

Despite several advances in allo-HSCT over the past few decades, GVHD remains the leading cause of NRM after transplant. Therefore, identifying valid and useful GVHD biomarkers for clinical use is still an unmet need.

Gl tract GVHD triggers a systemic inflammatory reaction and is thus the main driver of mortality. Recently, the Mount Sinai Acute GVHD International Consortium (MAGIC) validated an algorithm probability (MAP) tool derived from the combination of serum levels of two biomarkers of GI GVHD: ST2 and REG3a. When measured at the time of aGVHD diagnosis, the MAP separates patients into three distinct groups, known as Ann Arbor scores, each carrying a significantly different risk of 6-month NRM. Hence, the MAP can be considered as a "liquid biopsy" of the Gl tract damaged by the inflammation caused by GVHD and represents a more accurate quantitation of disease burden than clinical symptoms alone. Moreover, the threshold of probability value $(p \leq 0.291)$ calculated from these biomarker blood concentrations, taken 1 week after systemic treatment with steroids, was able to separate patients into groups with low and high probability of 12-month NRM, OS and resistance to steroid treatment at week 4. The MAP can also be calculated at day +7 , prior to the onset of aGVHD symptoms in any patient, and can predict NRM better than GVHD-related pre-transplant characteristics, such as HLA mismatch, unrelated donor, recipient age, and intensity of conditioning regimen ${ }^{46}$.

Giaccone and cols. ${ }^{47}$ summarized the recent evidence on the different types of biomarkers linked to acute and chronic GVHD. The authors highlighted the main markers and their types of interaction, as follows: genetic (minor histocompatibility antigens; association between single-nucleotide polymorphisms and genes involved in innate or adaptive immunity); plasmatic (reduced IL-15; increased: sIL-2R alpha, soluble B-cell activating factor [sBAFF], REG3a, ST2, TNFR1, Elafin, IL-8, CXCL9, CXCL10, CXCL11); cellular (reduced: Tregs, CD56 bright Natural Killer [NK] cells, CD27+ memory B cells, follicular helper T cells, invariant NK T cells; increased: CD4/CD8 ratio, Th17 lymphocytes, recent thymic emigrant or RTE CD4+CD45RA+CD31+ T cells, BAFF/B-cell ratio, CD19+CD$21^{\text {low }} B$ cells) and others associated with disruption of the microbiota (loss of bacterial diversity; expansion of a single taxon, as that of Enterococci, oral Actinobacteria and oral Firmicutes; and reduced levels of protective intestinal metabolites, such as urinary-3-indoxyl sulfate and butyrate).
Research efforts have been done to better understand the exact mechanism by which ATG prevents cGVHD. In a randomized, multicenter trial conducted by the Canadian Bone Marrow Transplant Group (CBMTG), ATG prophylaxis significantly impacted cGVHD cellular markers at day +100 in 40 patients (aged $\geq 16$ years). The ATG-treated group had a significant $>10$ fold decrease in both naive $T$ helper (Th) cells and RTE Th cells, which has been previously associated with moderate/severe CGVHD, and a 10-fold increase in CD56 ${ }^{\text {bright }} \mathrm{NK}_{\text {reg }}$ cells $(\mathrm{p}<.0001)$. Evaluation of Tregs, conventional Th cells, CD21 $1^{\text {low }} \mathrm{B}$ cells, and plasma markers (ST2, OSP, sBAFF, IL2Ra - sCD25, TIM-3, MMP3, ICAM-1, CXCL10, and soluble aminopeptidase N) revealed no impact of ATG on their concentration at day +100 . This analysis suggests that ATG primarily prevents cGVHD through suppression of naive Th cells (CD45RA + CD4+ T cells), with a concomitant expansion of noncytolytic CD56 bright $\mathrm{NK}_{\text {reg }}$ cells after transplantation ${ }^{48}$.

Bronchiolitis obliterans syndrome (BOS) is a pulmonary manifestation of CGVHD associated with high morbidity and mortality due to fibrosis of small airways and respiratory insufficiency. Pulmonary function tests have shown limited value for the diagnosis of BOS, particularly in children, since they are able to identify only the most severe cases. Therefore, plasma proteins correlated with BOS would be extremely valuable to enable early diagnosis, guide treatment choices, and monitor responses. A few cellular and plasmatic markers that correlate with BOS after HSCT, such as lung epithelial proteins, are being proposed for their diagnostic potential: matrix metalloproteinase-3 (MMP-3), Krebs Von Den Lungen-6 (KL-6), BAFF levels, and CD19+CD21 low B cells ${ }^{49}$.

KL-6 is a glycoprotein expressed on pulmonary epithelial cells that is undetectable in the serum of healthy individuals or only present in very small amounts. However, there is emerging evidence that epithelial cells of the proximal and distal air spaces of sick patients release host defence mediators that can facilitate the initiation of inflammatory airway changes; therefore, $\mathrm{KL}-6$ has been shown to be a useful serum marker for BOS after lung transplantation. Gassas and cols. ${ }^{50}$ conducted a prospective study to test KL- 6 and other plasma markers in allo-HCT recipients. Thirty-nine pediatric patients $(\leq 18$ years old) were included. They found that KL- 6 serum levels, measured before transplant or at 1 month post$\mathrm{HSCT}$, were significantly higher in surviving patients who developed BOS vs. in those who did not (preHSCT: mean, $32.6 \mathrm{U} / \mathrm{mL}$ vs. $5.8 \mathrm{U} / \mathrm{mL}, \mathrm{P}<.03$; at 1 month: mean, $52.5 \mathrm{U} / \mathrm{mL}$ vs. $11.4 \mathrm{U} / \mathrm{mL}, \mathrm{p}<.04)$. KL-6 levels at 3 and 6 months after HSCT remained higher 
in the BOS group but were not statistically significant $(p<.12)$. The high pre-HSCT levels of KL-6 in patients who later on developed BOS indicate that these patients are predisposed to develop this complication. The authors emphasized the importance of performing serum $\mathrm{KL}-6$ level measurements before transplant and at 1 month post-HSCT with a view to a timely identification of patients at a high-risk for BOS. Such patients may benefit from more frequent pulmonary surveillance and early therapy.

The Applied Biomarker in Late Effects of Childhood Cancer study (ABLE/PBMTC 1202) ${ }^{51}$ evaluated the immune profiles related to CGVHD and to late aGVHD (L-aGVHD). A peripheral blood immune cell panel and a set of plasma markers analyzed at day +100 correlated well with CGVHD diagnosed according to the $\mathrm{NIH}$ consensus criteria (NIH-CC). A total of 241 children were evaluable and categorized as L-aGVHD, cGVHD, active L-aGVHD or CGVHD, and no CGVHD/LaGVHD. Patients with only distinctive features but defined as having CGVHD by the adjudication committee (non-NIH-CC) had immune profiles similar to those of the NIH-CC. Both CGVHD and L-aGVHD had decreased transitional $B$ cells and increased cytolytic NK cells. Additional abnormalities were observed in cGVHD, such as: increased activated T cells, naive Th and cytotoxic T cells, loss of CD56 bright $\mathrm{NK}_{\text {reg }}$ cells, and increased ST2 and soluble CD13. Active L-aGVHD before day +114 had additional abnormalities in naive Th cells, naive Tregs, and in certain cytokines. On the other hand, active cGVHD had an increase in programmed cell death protein 1 (PD-1)-negative mem- ory Th cells and a decrease in PD-1-positive memory Tregs. An exploratory analysis appeared to show a progression of immune alterations from no CGVHD/ L-aGVHD to active L-aGVHD, with the most complex pattern seen in CGVHD. Comprehensive immune profiling might thus allow for the development of more specific strategies to minimize L-aGVHD and cGVHD. The same study group performed an additional analysis to compare $T$ cell populations across age groups and to evaluate the impact of the estimated pubertal status at the time of HSCT. In children, the authors observed a broad suppression of newly formed B (NF-B) cells, whereas adults exhibited an increase in $T 1-C D 21^{\circ} B$ cells and a decrease in T1-CD24 $4^{\text {hi }} C D 38^{\text {hi }} B$ cells. Pre-pubertal children had elevations of aminopeptidase N (sCD13) and ICAM1. Treg abnormalities in children appeared to occur primarily in memory Tregs, whereas in adults these abnormalities were seen in naive Tregs. It is probable that abnormalities in sex hormone levels post-transplant have an impact on immune reconstitution, since the onset of puberty seems to be the trigger for the decrease in thymic function. These findings support the role of pre-HSCT age and pubertal stage on the occurrence of CGVHD, and both may explain why pre-pubertal children have lower CGVHD rates, less aggressive disease, and biological differences in the pathways involved in the development of this complication ${ }^{52}$. Table 4 (modified from Cuvelier et al., $2020^{52}$ ) summarizes the differences in statistical correlation between cellular and plasmatic biomarkers and CGHVD according to pre-pubertal and pubertal stages at the time of transplant.

TABLE 4 - Cellular and Plasma Markers Significantly Associated with cGVHD According to Pubertal Status

\begin{tabular}{|c|c|c|}
\hline & Pre-pubertal & Pubertal1 \\
\hline \multicolumn{3}{|l|}{ Naïve T cells } \\
\hline . Naïve Th cells & Increased & Increased (NS) \\
\hline RTE naïve Th cells & Decreased & NS \\
\hline \multicolumn{3}{|l|}{ Newly formed B cells } \\
\hline . CD21lo B cells & Decreased & NS \\
\hline . T2 transitional & Decreased & NS \\
\hline . T3 transitional & Decreased & NS \\
\hline \multicolumn{3}{|l|}{ Peripheral B cells } \\
\hline . Mature Naïve & Decreased & NS \\
\hline - Unswitched memory/Marginal-zone like & Increased & Increased (NS)2 \\
\hline . Classical switched memory & NS & Increased (NS) \\
\hline \multicolumn{3}{|l|}{ Regulatory T cells } \\
\hline . PD1- memory Tregs & Increased & Decreased (NS) \\
\hline . PD1+ memory Tregs & NS & Increased \\
\hline
\end{tabular}




\begin{tabular}{|c|c|c|}
\hline . RTE memory Tregs & Decreased & NS \\
\hline . RTE naïve Tregs & NS & Increased (NS) \\
\hline Regulatory NK cells & Decreased & Decreased \\
\hline \multicolumn{3}{|l|}{ Cytokines and Chemokines } \\
\hline . ST23 & Increased & Increased \\
\hline Aminopeptidase N (sCD13) & Increased & Increased (NS) \\
\hline . ICAM-14 & Increased & NS \\
\hline
\end{tabular}

${ }^{1}$ Prepubertal was defined as a girl aged $<10.9$ years or boy $<12.4$ years and pubertal as a girl $\geq 10.9$ years or boy $\geq 12.4$ years at the time of HSCT. 2 NS $=$ Not statistically significant due to small number of patients. 3 Supressor of tumorigenicity-2. 4 Intracellular adhesion molecule 1.

\section{FIRST-LINE TREATMENT OF AGVHD}

The therapeutic approach toward a patient with aGVHD will depend on the organs and sites involved, GVHD grade, prophylactic regimen used, relative importance of the graft-versus-leukemia (GVL) effect (depending on the baseline disease), as well as on patient-related factors (e.g., renal impairment, coexisting infections, center expertise, and access to therapeutic alternatives) ${ }^{16}$.

\section{PEDIATRIC CONSIDERATIONS}

Even though the incidence of GVHD in children is generally lower than that in adults, roughly $50 \%$ of allogeneic transplants in the pediatric population are for the treatment of non-malignant diseases. In some of these disorders, such as in Fanconi anemia, repair systems are highly dysfunctional, which may impact the occurrence of GVHD. Moreover, specific recommendations both for the diagnosis and treatment of GVHD in children should be taken into account in the approach to these patients, such as the need for: adapting the BSA so as to allow for an accurate assessment of the cutaneous GVHD score; ruling out cases of transient macular rash due to viral infection (most common in children); quantifying diarrhea per episode ${ }^{53}$; and combining, whenever possible and indicated, non-pharmacological therapy (e.g., ultraviolet B phototherapy) and oral, non-absorbable corticosteroids (oral budesonide and beclomethasone), with the aim of reducing both the exposure time to and cumulative dose of systemic corticosteroids ${ }^{11}$.

Treatment of grade I aGVHD: the first approach is to optimize the prophylaxis regimen used, by adjusting CNI trough levels and adding topical agents (corticosteroids or tacrolimus) accordingly. Adjuvant supportive therapy with anti-hystaminics for controlling pruritus, for instance, may be helpful. No systemic immunosuppression is recommended ${ }^{54}$.
Treatment of grade II-IV aGVHD: the initial treatment does not differ between adults and children. Systemic treatment with methylprednisolone (MP) at a dose of $2 \mathrm{mg} / \mathrm{kg} /$ day or its prednisone equivalent should be promptly initiated upon diagnosis ${ }^{55}$. Concomitant CNI (CsA or tacrolimus) prophylaxis should not be withdrawn, and trough levels should be checked for. For less severe forms (i.e., grade lla aGVHD), starting MP at a dose of $0.5-1 \mathrm{mg} / \mathrm{kg} /$ day is acceptable, with close monitoring and possible escalation up to $2 \mathrm{mg} / \mathrm{kg}$ if worsening occurs after $72 \mathrm{~h}^{56,57}$. Non-absorbable glucocorticoids (beclomethasone and budesonide) have also been used in the treatment of mild upper or lower GI aGVHD (10.0-19.9ml/kg/day or 4-6 episodes/stool output/ day in children) as an adjuvant to systemic corticosteroids $^{58,59}$. Unfortunately, only around $60 \%$ of patients favorably respond to first-line treatment, and many of such responses are not durable ${ }^{60}$. These patients are considered steroid-refractory and should then undergo second-line therapy.

\section{SECOND-LINE TREATMENT OF GRADE II-IV AGVHD}

Second-line treatment is recommended in case of aGVHD progression within the first three days $(72 \mathrm{~h})$ or of lack of improvement after 5-7 days after initial therapy with MP $2 \mathrm{mg} / \mathrm{kg} /$ day, in combination with an optimized-level $\mathrm{CNI}$, as mentioned above ${ }^{30}$. Studies on the second-line treatment of aGVHD in children are scarce, predominantly retrospective, with poor historical controls, and, as in adults, highly heterogeneous, with great variability across institutions. Since no superiority of one agent over another has been proven to date in this population, the choice of the most appropriate approach should be individualized and dependent upon the following factors: comorbidities, previous therapy, drug interaction, availability, accessibility, and center expertise ${ }^{30}$. Steroid-refractory aGVHD has typically a poor progno- 
sis, both in adults and in children, given the high treatment-failure rates in this scenario. Overall, the average response to second-line agents is around $50 \%$, with a median OS of $\sim 60 \%$ at 6 -months, with or without active disease ${ }^{61,62}$. The 1-year OS in this population is approximately $20-30 \%{ }^{61}$. The main results seen with these agents are depicted below.

MMF: this drug acts by inhibiting the synthesis of guanosine triphosphate, a key enzyme involved in T-cell proliferation. MMF was one of the four drugs tested in the phase II, randomized-controlled BMT CTN 0302 trial, while assessing its possible role in first-line therapy in combination with MP. ${ }^{63}$ In a subsequent phase III study, BMT CTN 0802, no significant benefit was seen in GVHD-free survival, nor in the cumulative incidence of cGVHD at 12 months $^{61}$. Retrospective studies showed complete and partial response (PR) rates of up to $77 \%$ at 6 -months. MMF may hence be considered in select cases as a second-line approach ${ }^{64,65}$.

Extracorporeal photopheresis (ECP): this treatment modality uses ultraviolet $A$ rays to irradiate circulating lymphocytes during leukapheresis after ex vivo incubation with 8-methoxypsoralen (8-MOP). This leads to lymphocyte apoptosis (including that of alloreactive T-cells) within 24 hours after reinfusion due to subsequent phagocytosis by antigen-presenting cells (APCs), which produce immunomodulatory effects through cytokine regulation and immune-tolerance induction via Treg expansion, as seen in murine models $s^{66,67}$. Of note, there are no solid data pointing to an increase in the risk of opportunistic infections, nor of loss of the GVL effect, with ECP, given its immunomodulatory, as opposed to immunosuppressant, properties ${ }^{68,69}$. Several retrospective studies to date have shown the favorable results of ECP in the management of steroid-refractory aGVHD, with complete response (CR) rates varying between 54 to $75 \%{ }^{67,70}$. This is particularly true for cases with skin involvement, in which $C R$ rates reach up to $90 \%{ }^{71}$. In a retrospective, multicenter study including 98 patients with steroid-refractory aGVHD receiving either ECP or anti-cytokine therapy, ECP was shown to be superior, with a CR rate of $54 \%$ vs. $20 \%$, respectively ${ }^{72}$. Another study which included 21 patients undergoing ECP therapy, a CR of 100\% and $67 \%$, respectively, was observed for those with grade II/III aGVHD. ${ }^{73}$. In a prospective, phase II study published in 2006, which included 59 patients with steroid-refractory or steroid-dependent aGVHD, a CR was observed in $82 \%$ of patients with skin involvement and in $61 \%$ of those with hepatic or Gl tract involvement ${ }^{68}$. A fairly recent meta-analysis including nine prospective studies and a total of 323 patients showed favorable results, particularly for the treatment of GVHD of the skin (84\%) and GI tract (65\%) ${ }^{74}$. As for the time to observed response, the Spanish group showed early ECP responses, of which $80 \%$ occurred within the first 6 months of therapy. This was further corroborated by Greinix and cols., with a significant response being noted after an average of 4 cycles of ECP ${ }^{68}$. Nonetheless, studies specifically addressing the pediatric population are still lacking. Overall, the current evidence, for both adults and children, support the fact that the clinical response to ECP depends mainly on the grade and extent of aGVHD and on the time until initiation of therapy after diagnosis of refractoriness to first-line steroid therapy ${ }^{75}$.

ATG: polyclonal and monoclonal antibody-based therapies are among the most widely used second-line agents for GVHD and with which considerable experience has been gained over the past three decades or so. Nonetheless, response rates seldom reach more than $50 \%$, given that most studies exhibit response rates between $20 \%$ and $50 \%$, with slightly better results for cutaneous acute GVHD ${ }^{76,77}$.

Anti- IL-2Ra antibody therapy: the potential role of IL-2Ra antibody therapy for aGVHD is based on the molecular structure of this antibody in that its alpha subunit (CD25) is found predominantly in activated (alloreactive) T-cells. Basiliximab, as a chimeric IL2Ra antagonist, has shown some promising results, with CR rates of up to $71 \%$ in a phase I study with a small number of patients ${ }^{78}$. Funke et al. observed an overall response rate (ORR) of $80 \%$ and a 5 -year OS of $30 \%$ among 34 patients with refractory grade III-IV $\mathrm{aGVHD}^{79}$.

TNF antagonists (Infliximab, Etarnecept): TNF antagonists seem particularly useful for the management of steroid-refractory GVHD involving the $\mathrm{Gl}$ tract, with a number of case series, one of which showed an ORR of $70 \%$ in 37 patients $^{80}$.

Ruxolitinib: this Janus kinase (JAK) inhibitor has been shown fairly recently to be efficacious and safe in the treatment of refractory cases of both acute and chronic GVHD ${ }^{81,82,83}$. It was also shown to exert an inhibitory effect over interferon-gamma (IFN- $\gamma$ ) receptor (IFNGR) signalling pathways, which are known to be implicated in the effect of alloreactive T-cells in the pathogenesis of aGVHD. Similarly, Janus kinases (JAKs) are involved in all three pathophysiological phases of aGVHD, since they interfere with common cytokine production and signalling pathways, as well as with the development and function of nonT-cell immune effectors, such as APCs ${ }^{84}$. Importantly, JAK-STAT (signal transducer and activator of transcrip- 
tion) inhibition in preclinical models showed an improvement in aGVHD, while the GVL effect seemed to remain unaltered, with its obvious advantages ${ }^{85}$. Over the past decade, two pivotal studies - REACH 1 and REACH 2 - enabled ruxolitinib to become, in 2019, the first second-line treatment approved by the Food and Drug Administration (FDA) as an alternative to the management of steroid-refractory grade II-IV aGVHD $86,87,88$. REACH1 was a prospective, phase I, single-arm study which reported an ORR (CR and PR) of $54.9 \%$ on D+28 and an OS at 6 months of $73 \%$. Cytopenia and viral reactivation were the most common adverse events observed. ${ }^{86} \mathrm{REACH} 2$, in turn, was a much larger, multicenter, phase III, randomized-controlled study, which compared the efficacy of ruxolitinib (20mg/day) with nine commonly used salvage therapies for steroid-refractory aGVHD (at physicians' discretion). A total of 309 patients were randomized, with a statistically significantly higher ORR at D+28 $(62 \%$ vs. $39 \%$, OR: $2,64,95 \% \mathrm{Cl} 1.65-$ $4.22, p<0.0001)$ and at $D+56(40 \%$ vs. $22 \% ; p<0.05)$ as compared to controls. After a 6-month follow-up period, $10 \%$ of patients in the ruxolitinib arm lost their response to therapy, as opposed to $39 \%$ in the control group ${ }^{88}$. More recently, ruxolitinib was assessed in a study of 29 pediatric patients with steroid-refractory grade II, III-IV aGVHD or CGVHD and showed rather astonishing results, with response rates of $80 \%, 82 \%$ and $100 \%$, respectively, with initial doses of $5 \mathrm{mg}$ or $10 \mathrm{mg} /$ day, according to body weight $(<15 \mathrm{~kg}$ or $\geq 15 \mathrm{~kg}$ ), and possible dose escalation to $20 \mathrm{mg} /$ day, if tolerable, regardless of weight. Data on the pharmacokinetics of ruxolitinib in this population, however, are still pending in order to better define the optimal dosing of this inhibitor and the most appropriate schedule for immunoglobulin $\mathrm{G}(\mathrm{IgG})$ serum level monitoring ${ }^{89}$. Of note, children under ruxolitinib therapy should receive appropriate antimicrobial prophylaxis and be closely monitored and followed up for possible intervening infections.

\section{DIFFERENTIAL DIAGNOSIS BETWEEN ACUTE AND CHRONIC GVHD}

The classification of GVHD in classic and late or recurrent forms proposed by the $2005 \mathrm{NIH}$ Consensus ${ }^{1}$ was not changed in the 2014 Consensus ${ }^{3}$. It includes: (1) classic GVHD (erythema, maculopapular lesions, nausea, vomiting, anorexia, diarrhea, paralytic ileus, or cholestatic liver disease) that appears before 100 days after HSCT or after donor lymphocyte infusion (DLI), without distinct signs or diagnosed CGVHD; (2) Late, persistent or recurrent GVHD: classical GVHD presentation, which occurs after 100 days of HSCT or DLI (often after decrease or withdrawal of immunosuppression) without distinct signs or diagnosed cGVHD. Overlap GVHD occurs when both acute and chronic GVHD features are present. It is generally correlated with a worse prognosis and an adverse impact on OS. There is no time limit for its onset.

TABLE 5 - Acute and Chronic GVHD Categories

\begin{tabular}{c|c|c|c|c}
\hline \multicolumn{2}{c|}{ Category } & Time of onset & aGVHD & cGVHD \\
\hline \multirow{2}{*}{ aGVHD } & Classic & $<100$ days & Yes & No \\
\cline { 2 - 5 } & Persistent/Recurrent/Late Acute & $>100$ days & Yes & No \\
\hline \multirow{2}{*}{ CGVHD } & Classic (De Novo/ Quiescent/Progressive) & No limit & No & Yes \\
\cline { 2 - 5 } & Overlap & No limit & Yes & Yes \\
\hline
\end{tabular}

Legend: aGVHD: acute graft-versus-host disease; CGVHD: chronic graft-versus-host disease; persistent (previously unresolved aGVHD); recurrent (previously resolved aGVHD); late acute (without prior aGVHD); classic and overlap cGVHD: de Novo (without prior aGVHD); quiescent (previously resolved aGVHD); progressive (previously unresolved aGVHD)

\section{DIAGNOSIS AND INDIVIDUAL ORGAN PRESENTATION OF CGVHD}

As a rule, distinguishing between acute and chronic GVHD basically depends on the clinical manifestations rather than the time point at which they present after $\mathrm{HSCT}^{1}$. Presenting signs and symptoms may be termed "diagnostic", when they allow for a prompt diagnosis of CGVHD, regardless of any additional testing or organ involvement; "distinctive", which are commonly present in CGVHD and not in aGVHD but are not enough for a definitive diagnosis of CGVHD; and "common", when features of both chronic and acute GVHD are present at the same time ${ }^{3,90}$. A diagnosis of CGVHD is obtained when at least one of such diagnostic manifestations is observed or at least one distinctive manifestation is confirmed with a histopathological examination or with laboratory tests, or, yet, upon specialized evaluation (e.g., with a gynecologist or ophthalmologist) or radiological examination of the same or of different sites ${ }^{3,90}$. 
From the pathophysiological standpoint, cGVHD involves an array of phenomena comprising inflammation, cellular and humoral responses, and fibrosis. This way, it closely resembles autoimmune diseases of the collagen vascular type. Disease onset is more commonly seen during the first year post-transplant but may also be noted several years after $\mathrm{HSCT}^{9}$.

Clinical manifestations of cGVHD may be limited to a single organ or site, or may be widespread, with disseminated disease potentially leading to a severe quality of life (QoL) burden for the patient ${ }^{91,92}$.

Of note, cGVHD must be clearly differentiated from post-transplant infectious complications, such as those due to fungal or viral infections, or yet from other causes, such as those related to drug toxicity, disease relapse, or secondary malignancy.

It may involve virtually any organ or site, the most common of which being the skin, mouth, hair/scalp, nails, eyes, Gl tract, genitalia, liver, lungs, muscles, fasciae, and joints, hematopoietic and immune system, among others ${ }^{1,3,90}$. As mentioned previously, the NIH consensus statements from 2005 and 2014 offer a comprehensive guide for the appropriate identification of the diagnostic, distinctive, and common features of c GVHD, as well as for the grading process based on the specific organ/ site involvement observed ${ }^{1,3}$.
An accurate diagnosis and grading of cGVHD may be quite challenging, given the uncertainties related to the pathophysiology of this disease and the common coexistence of aGVHD manifestations. This is further aggravated by the lack of a robust validation of the current grading tools and biomarkers for the diagnosis and risk assessment of this post-transplant complication ${ }^{3}$.

\section{GLOBAL SEVERITY SCORE OF CGVHD}

The NIH global severity score for cGVHD was first proposed in 2005 and later revised and updated in $2014^{1,3}$. In this grading system, the score varies from 0 to 3 at each organ or site involved, comprising a total of eight sites (skin, eyes, gut, liver, lungs, joints, fasciae, and genitourinary tract) The global score takes into account both the number of organs or sites involved and the severity of involvement at each organ/site ${ }^{1,3}$.

According to the total score obtained, the CGVHD observed may be classified as mild, moderate, or severe, which will reflect the degree of impact and functional impairment at each organ or site involved. ${ }^{3,90}$. Importantly, cGVHD should be graded at diagnosis and during follow-up, hence allowing for clinical severity and prognostic re-evaluation in a timely manner ${ }^{3,90}$. Table 6 depicts the global severity scoring system of cGVHD.

TABLE 6: NIH global severity score of cGVHD

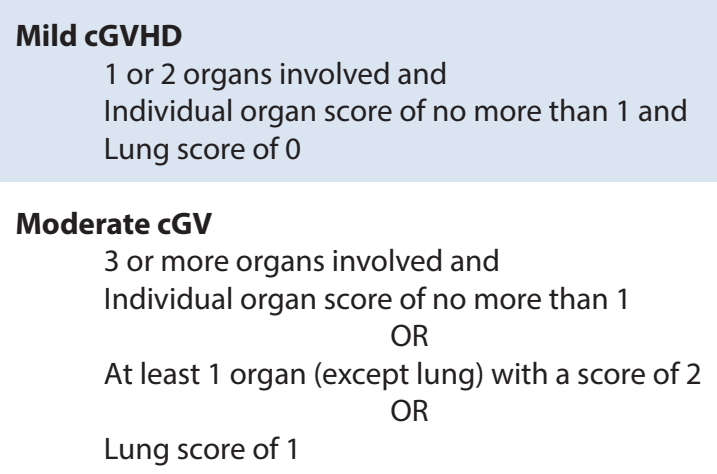

\section{Severe cGVHD}

At least 1 organ with a score of 3

OR

Lung score of 2 or 3

\section{Key points:}

Skin: the highest of the two scores should be used for calculating global severity.

Lung: FEV1 should be used instead of the clinical score for calculating global severity.

If the abnormality in an organ is considered to be unequivocally explained by a non-GVHD cause, its corresponding score will be zero and thus not included for calculating global severity.

If the abnormality in an organ is attributed to multifactorial causes (GVHD plus other causes), its corresponding score will be used for calculating global severity regardless of the contributing causes (without any downgrading of organ severity score). 


\section{TREATMENT OF CGVHD}

No systemic treatment is needed for cases of asymptomatic, mild cGVHD. In such cases, topical steroids, for instance, for skin, mouth, or genital involvement, may be applied, with close monitoring for possible signs of disease progression at other sites so as to avoid clinical deterioration due to suboptimal treatment ${ }^{3,90}$. A prompt intervention might thus help prevent CGVHD progression ${ }^{3,90}$.

In patients with three or more organs/sites involved, or with a global NIH score of 2 or more, at whatever site, systemic immunosuppression should be promptly initiated ${ }^{3,90}$.

For patients with a diagnosis of de novo CGVHD, possible alternatives are to increase the dose of the immunosuppressant being used and/or to add another immunosuppressant ${ }^{3,90}$.

To date, chronic GVHD remains one of the main drivers of late post-allogeneic transplant morbidity and mortality. Some of the main risk factors for a higher transplant-related mortality are: multiple organ involvement, low performance status, low platelet count at diagnosis of GVHD $(<100.000 / \mu \mathrm{L})$, hyperbilirubinemia, CGVHD progressing from prior aGVHD, extensive skin involvement at diagnosis of GVHD,

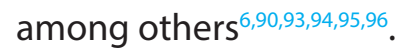

Patients presenting with cGVHD are more prone to infectious complications due to the intense immunosuppression they are submitted to, as well as the functional asplenia and hypogammaglobulinemia that typically accompany the post-transplant period $^{90,92}$. This results in infections being the predominant cause of mortality in these patients. Therefore, all patients with a diagnosis of CGVHD should receive appropriate Pneumocystis jirovecii pneumonia prophylaxis, as well as vaccines against encapsulated bacteria, namely Meningococcus sp., Haemophilus sp., and Pneumococcus sp, coupled with human immunoglobulin replacement at regular monthly intervals, as needed ${ }^{90,92}$. When presenting with fever, patients with CGVHD need to be promptly evaluated and treated, due to the risk of sepsis and of rapid clinical deterioration ${ }^{90,92}$.

The main goal of the treatment of cGVHD is to reduce its corresponding symptoms, control disease progression, and prevent harm or disability ${ }^{3,90}$. Treatment intensity will depend on both the extension and severity of the disease. The $2014 \mathrm{NIH}$ Consensus Guidelines addresses the severity criteria and grading of the disease, thus aiding in the decision-making process as to whether topical or systemic treatment should be applied ${ }^{3}$. In patients presenting with only mild symptoms, limited to a single organ or site, it is acceptable to adopt a conservative, watch and wait approach, or to use topical therapy alone, whereas, for patients with a worse clinical picture or multiple organ involvement, systemic treatment is warranted. ${ }^{3,90}$. The management of cGVHD may be quite challenging, and caution should be taken to keep systemic immunosuppression to the least degree possible, with the aim of controlling the disease until immunological tolerance is established between donor and recipient ${ }^{3}$; less immunosuppression allows for a lower rate of severe infections.

Some key points ought to be emphasized when managing CGVHD in the pediatric population, one of which is the potential long-term effects of highdose steroid therapy. Another aspect is that of children who undergo HSCT for non-malignant diseases, wherein the GVL effect coexisting with GVHD is unnecessary ${ }^{97,90}$.

Since cGVHD often involves several organ systems, a multidisciplinary approach to the management of this disease is of at most importance and should generally include physical therapy, psychological, nutritional, dental, social and occupational therapy support ${ }^{98}$.

TABLE 7. Indications for systemic therapy of chronic GVHD 3,90,99

\begin{tabular}{c|c|c}
\hline Global severity & High mortality risk * & Systemic therapy \\
\hline Mild & No & Yes $\neq$ \\
\hline Mild & No/Yes & Yes \\
\hline Moderate & No/Yes & Yes \\
\hline Severe & & \\
\hline
\end{tabular}

Legend: GVHD: graft-versus-host disease.

* Platelets $<100,000 / \mu \mathrm{L}$ or under steroid therapy at the time of diagnosis of GVHD

$\neq \mathrm{A}$ balance between the potential benefit of graft-versus-leukemia effects and the risk of GVHD should be sought 


\section{FIRST-LINE TREATMENT}

According to the $2014 \mathrm{NIH}$ Consensus criteria, systemic treatment of cGVHD should be administered for cases with: score $>2$ in any organ, involvement of three or more organs, and mild cGVHD with highrisk features (platelet count $<100,000 / \mathrm{mm} 3$ and use of immunosuppression at the time of the diagnosis of (GVHD) ${ }^{94}$.

First-line systemic treatment consists of $1 \mathrm{mg} / \mathrm{kg} / \mathrm{day}$ prednisone (or its equivalent) and CsA (or tacrolimus), with dose adjustment for serum level ${ }^{100}$. There is no solid evidence that the addition of another immunosuppressant (MMF, azathioprine, or thalidomide) to first-line therapy improves the results, in which case this should not be done ${ }^{20}$. After a two-week period, if there is a response to therapy or the condition is stable, one should start tapering the dose of steroids every other day, with a weekly reduction of $25 \%$, for 6 to 8 weeks, until a dose of $0.1 \mathrm{mg} / \mathrm{kg} /$ day is reached. According to the Fred Hutchinson Cancer Research Center (FHCRC), this dose should be maintained for 2 to 3 months, in case of incomplete response, severe presentation, or GVHD-related risk factors. ${ }^{99}$ This should then be followed by a second period of dose tapering, with a dose reduction of 10 to $20 \%$ a month, until total withdrawal after 9 to 12 months ${ }^{99}$. When other immunosuppressants are being used concomitantly, these should be sequentially tapered, after steroid withdrawal, for a period of 2 to 4 weeks, until complete withdrawal ${ }^{90}$.

Steroid-refractory CGVHD is defined as progression of disease after a two-week period under $1 \mathrm{mg} / \mathrm{kg} /$ day of steroids, whereas stable disease is considered when a dose of $>0.5 \mathrm{mg} / \mathrm{kg} /$ day is used for 4 to 8 weeks or when one does not tolerate a prednisone dose $<0.5 \mathrm{mg} / \mathrm{kg} / \mathrm{day}^{101}$

Second-line therapy for cGVHD is indicated when at least one of the following criteria are met: worsening of cGVHD at a primarily involved organ or site, lack of response to therapy after a 1-month period, or inability to reduce the dose of prednisone to levels below $1 \mathrm{mg} / \mathrm{kg} /$ day for a period of 2 months ${ }^{97}$.

\section{SECOND-LINE THERAPY AND NOVEL TREATMENTS FOR CGVHD}

There is currently no optimal treatment choice for second-line therapy for CGVHD. Choice of treatment will depend on several factors, such as: organ or site involved, toxicity profile, center expertise, treatment availability, and patient preference. One should not start a third treatment (e.g., immunosuppressant) before an observation period of two to three months so as to better assess response to each therapy90,99. The main second-line treatment options for CGVHD are:

- ECP: ECP constitutes an effective treatment modality for refractory or steroid-dependent CGVHD, both in adults andchildren ${ }^{102}$. It is considered a good option for the second-line approach to patients who are dependent upon, intolerant to, or, yet, resistant to corticosteroids. It may also be considered for cases with recurrent infections or at a high risk of relapse of their baseline disease. ECP has been shown to be particularly effective in mucocutaneous CGVHD, with CR rates of up to $80 \%$, as well as a good response in sclerotic forms of this disease ${ }^{103,73}$. Response rates also tend to be high in CGVHD with mouth, eye, and liver involvement, with a response rate of $70 \%, 60 \%$, and $68 \%$, respectively ${ }^{104,105}$. Moreover, ECP has been shown to enable dose reduction of chronic steroid therapy in select cases ${ }^{73,106,107,108}$. On the other hand, ECP should not be performed in patients with a total white blood cell count of $<1000 / \mathrm{mm}^{3}$, intolerance to 8-MOP, heparin, or citrate, and/or in those who are hemodynamically unstable ${ }^{109}$. ECP has been shown to be well tolerated in children, with a low rate of, typically mild, side-effects, even in low- or underweight patients ${ }^{110}$. Most often, treatment is interrupted due to a lack of an appropriate vascular access, which can usually be managed by insertion of a large-caliber and rigid-type central venous catheter ${ }^{30}$. Hence, ECP is a both feasible and safe treatment option for cGVHD in children, with favorable results. Some studies have suggested the use of ECP as a possible first-line therapy option for refractory or moderate/ severe cGVHD in specific clinical situations ${ }^{111,112}$.

\section{- Mammalian target of rapamycin (mTOR) recep-} tor inhibitors: the most commonly used agent within this class is sirolimus (rapamycin). It is generally used in combination with a $\mathrm{CNI}$, with response rates varying from $56 \%$ to $81 \%{ }^{113}$. However, since it is used in association with a $\mathrm{CNI}$, its serum level should be closely monitored, given the increased risk of thrombotic microangiopathy with this combination ${ }^{113}$. Other relatively common side-effects of this medication include dyslipidemia, renal dysfunction, and cytopenia ${ }^{90}$. Caution should be taken regarding potential drug-drug interactions with sirolimus, for which close serum level monitoring and dose-adjustment should be performed accordingly.

- Low-dose MTX: MTX has long been used in a number of autoimmune disorders, with favorable results. This led several investigators to assess its potential role, at low doses, in the management of cGVHD, 
both in adults and children ${ }^{114,115}$. Recommended doses vary from 5 to $10 \mathrm{mg} / \mathrm{m}^{2}$ of BSA at weekly intervals or every 3 to 4 days, with partial or complete responses achieved ${ }^{115,116}$. Some authors reported favorable results with a dose of $7.5 \mathrm{mg} / \mathrm{m}^{2} /$ week for refractory cGVHD, with a low toxicity profile and allowing for dose tapering of steroids. ${ }^{114}$. These results have also been reproduced in children ${ }^{115}$. MTX was well tolerated and exhibited a low rate of grade III-IV hematologic toxicity and grade II hepatotoxicity ${ }^{115}$. Current studies have shown that the best response rates tend to be obtained in the treatment of skin and mouth cGVHD, with no apparent increase in the risk of relapse of baseline disease $\mathrm{e}^{114,115,116}$.

- Tacrolimus: CNIs are generally used in association with corticosteroids as first-line treatment of CGVHD. Their use as second-line therapy is fairly limited and has provided somewhat modest results ${ }^{117}$. Switching from CsA to tacrolimus has not significantly improved these results, except for a single study which showed a $20 \%$ improvement in overall response ${ }^{118}$.

- MMF: the ORR in CGVHD with this immunosuppressant has varied between 23 and $79 \%$ in several case series $^{90,119,120,121}$. The most often observed side-effects of MMF comprise both hematologic and GI toxicity, including the development of ulcers of the intestinal mucosa ${ }^{90}$. Infection rates also tend to increase with this medication, particularly viral infections ${ }^{122,65}$.

- Rituximab: as a chimeric, humanized anti-CD20 monoclonal antibody (MoAb), it exerts its anti-GVHD effect by depleting autoreactive B-cells. A prospective study by Cutler et al., 2006, showed favorable response rates of rituximab at a dose of $375 \mathrm{mg} / \mathrm{m}^{2}$ in patients with refractory $\mathrm{CGVHD}$, with the additional benefit of allowing for significant steroid tapering ${ }^{123}$. The best responses were observed for GVHD of the skin, particularly in its lichenoid form, and for musculoskeletal GVHD ${ }^{123}$. Most studies recommend a weekly dose of $375 \mathrm{mg} / \mathrm{m}^{2}$ for 4 to 8 weeks ${ }^{124,125}$. The most common side-effects relate to infusion reactions and infectious complications ${ }^{123}$.

- Imatinib: this tyrosine-kinase inhibitor has been used as a potential alternative for the treatment of CGVHD, given its anti-platelet derived growth factor receptor (PDGFR) and anti-transforming growth factor receptor beta (TGFB) effect and, thus, its antifibrotic effect ${ }^{90}$. The current evidence has shown favorable results with the use of imatinib for sclerotic-type cGVHD of the skin ${ }^{126,127}$. The recommended dose varies between $100 \mathrm{mg}$ and $400 \mathrm{mg} /$ day, which is equivalent to a dose of $65 \mathrm{mg} / \mathrm{m} 2$ to $260 \mathrm{mg} / \mathrm{m}^{2} /$ day in pediatric patients. ${ }^{90,128}$ Some of the most com- mon side-effects of this medication include hematologic toxicity, fluid retention, and dyspnea ${ }^{90}$.

\section{- Low-dose (100-150cGy) thoracoabdominal irra-} diation (TAI): given its immunosuppressive and immunomodulatory effects, this therapeutic modality can be used in patients with refractory cGVHD ${ }^{129,130}$. The best responses are seen for mucocutaneous cGVHD, particularly for fasciitis and GVHD of the mouth. TAl has also been shown to allow for systemic steroid tapering ${ }^{90,130}$.

Ruxolitinib: this Janus kinase (JAK) inhibitor has more recently been shown to be efficacious and safe in the treatment of refractory cases of both acute and chronic GVHD ${ }^{81,82,83}$. In a muticenter study by Gomez et al., 2020, ruxolitinib showed an ORR of 57\% inr the treatment of CGVHD, but only a $4 \%$ CR rate was achieved after a median of 4 weeks follow-up ${ }^{81}$. Steroid tapering was possible among $57 \%$ of cases $^{81}$. The OS rate at 1 year was $81 \%$. Of note, this comprised a heavily pre-treated population, with several lines of therapy for GVHD. In a recent study by Yang et al., 2021, which included a total of 53 pediatric patients with acute or chronic GVHD who had had a poor response to prior therapy, ruxolitinib had an ORR of $75.5 \%$, which reached $80.6 \%$ in those with cGVHD. Among these, 10 were complete responses and 19 were partial responses ${ }^{82}$. Additionally, a total of $39 \%$ of cases were able to have their steroids withdrawn ${ }^{82}$. A possible drawback of ruxolitinib is the potential increase in the rate of opportunistic infections due to its anti-T-cell effect. In a study assessing children with acute or chronic GVHD receiving ruxolitinib, an ORR of $77 \%$ and $89 \%$ was observed, respectively ${ }^{83}$. In these children, ruxolitinib was shown to increase CD4+-memory B-cells, decrease CD4+-Tregs, decrease CD8+-T-cells, and reduce NK cells, with a resulting increase in the occurrence of infections, with a rate of $54 \%, 18 \%$, and $13 \%$ of viral, bacterial, and fungal infections, respectively ${ }^{83}$. Therefore, children under ruxolitinib therapy for GVHD should receive appropriate antimicrobial prophylaxis and be closely monitored and followed up for possible intervening infections. In a recent publication from Brazil, Ferreira et al. reported the experience of ruxolitinib in a cohort of 35 adult patients with corticosteroid-refractory cGVHD from two transplantation centers, with the longest follow-up described to date ${ }^{131}$. The patients had a median of 3 organs affected (range, 1 to 7 organs), with most (64\%) having moderate CGVHD. The median number of previous therapy lines was 2 (range, 1 to 6). The ORR was $89 \%$ (CR, 26\%) after a median of 4 weeks of therapy. The median follow-up was 43 months (range, 11 to 59 
months). At follow-up, of the 27 patients still alive, $18(67 \%)$ were free of any immunosuppression, and $6(22 \%)$ were receiving ruxolitinib as their sole immunosuppressive drug. Failure-free survival (FFS) was $77 \%$ at 6 months, $68 \%$ at 12 months, $54 \%$ at 24 months, and $51 \%$ at 36 months. Toxicities were mostly hematologic and resolved after dose reduction in most cases, supporting the use of this drug as a safe and effective option for refractory cGVHD ${ }^{131}$.

- Ibrutinib: this Bruton-tyrosine kinase inhibitor has been extensively studied in the past several years and has been shown to be of benefit in adult patients harboring refractory or steroid-dependent cGVHD. Currently, it is the only FDA-approved therapy for adults failing at least one prior line of systemic therapy for cGVHD ${ }^{132,133,134}$. In a study by Waller et al., 2019, which evaluated 42 patients with refractory or steroid-dependent CGVHD receiving ibrutinib at a dose of $420 \mathrm{mg} /$ day over a follow-up period of 26 months, an ORR of $69 \%$ was noted, of which $31 \%$ were complete responses and 38\% were partial ones ${ }^{132}$. Moreover, a sustained response was observed after 44 weeks of treatment in $55 \%$ of these patients. Patients with two or three organs involved had a response rate of $73 \%$ and $60 \%$, respectively. Of note, in this study, ibrutinib enabled a dose reduction of steroids to $<0.15 \mathrm{mg} / \mathrm{kg} /$ day in $64 \%$ of patients, and complete withdrawal was possible in $19 \%$ of cases $^{132}$. As for the side-effects of ibrutinib, pneumonia, fatigue, diarrhea, nausea and vomiting, muscle cramps, and hematomas were among the most commonly reported ones ${ }^{132,133}$. After a mean follow-up of over 2 years, patients with cGVHD who had failed a prior line of therapy continued to show durable responses while on ibrutinib ${ }^{132,133}$. There are no robust data as yet, however, as to the ideal dose and safety of this medication in the pediatric population. In a retrospective study published in 2020, where 22 children with predominantly moderate or severe CGVHD received ibrutinib at a daily dose of $250 \mathrm{mg} / \mathrm{m}^{2}$ per day, a total of eight (36\%) children had their medication withdrawn due to adverse events or died. Among the 14 evaluable patients, 12 (86\%) achieved a PR after a follow-up of 6 months. Notably, Epstein-Barr virus (EBV) reactivation occurred in one of these patients and pneumococcal sepsis in another, despite appropriate antimicrobial prophylaxis. The authors concluded that, although the results of ibrutinib for the treatment of CGVHD in children are seemingly promising, further studies addressing the pharmacokinetics of this tyrosine-kinase inhibitor are warranted so as to better define its efficacy and optimal dosing in this population ${ }^{135}$.
- Mesenchymal stem cells (MSCs): given their potent immunomodulatory properties, especially for their effector function inhibition, MSCs have risen as a promising alternative for the management of immune-mediated disorders, including GVHD ${ }^{136}$. These cells provide the necessary support for stem cell growth and differentiation within the bone marrow milieu, and they are also able to suppress the proliferation of reactive lymphocytes without Major Histocompatibility Complex (MHC)/HLA restriction ${ }^{90,137,138}$. There have been a number of publications reporting successful responses with MSC infusion for the treatment of CGVHD, with an ORR of around $70 \%$ and the additional advantage of enabling dose reduction or complete withdrawal of the prior immunosuppressants being used ${ }^{139,140}$. These results have been particularly encouraging in patients with cutaneous, pulmonary, liver, mouth, and eye involvement ${ }^{140,141}$. Durable response rates have also been reported ${ }^{142}$. In a study by Krasowska-Kwieciena et al., 2019, nine children with severe acute or chronic GHVD who were resistant to corticosteroids and second-line immunosuppressants were assessed for their response to MSC infusion ${ }^{143}$. In this study, children received between one and six MSC infusions, with no infusion-related adverse events and an ORR rate of $56 \%$ after the first infusion and of $44 \%$ after the end of treatment ${ }^{143}$ Patients presenting with cGVHD of the skin, GI tract, and liver had a CR rate of 50\%, 38\%, and $33 \%$, respectively ${ }^{143}$.

- Belumosudil: this is a selective oral inhibitor of Rho-associated coiled-coil kinase-2 (ROCK2), a signaling pathway that modulates inflammatory response by regulating Th17/Treg balance and fibrotic processes, which led to its investigation for the management of cGVHD. Belumosudil reduces type 17 and follicularTh cells via downregulation of STAT3 and enhances Treg function via upregulation of STAT5 ${ }^{144,145}$. Jagasia et al., 2021, published the results of a phase Ila, open-label, dose-finding study of belumosudil, which enrolled 54 patients with CGVHD who had received one to three prior lines of therapy ${ }^{144}$. The primary endpoint was ORR. The median time from cGVHD diagnosis to enrollment was 20 months. Seventy-eight percent of patients had severe CGVHD, $50 \%$ had $\geq 4$ organs involved, $73 \%$ had cGVHD refractory to their last therapies, and $50 \%$ had received $\geq 3$ prior lines of therapy. With an overall median follow-up of 29 months, the ORR with belumosudil 200 mg once daily, $200 \mathrm{mg}$ twice daily, and $400 \mathrm{mg}$ once daily was $65 \%, 69 \%$, and $62 \%$, respectively. Responses were clinically meaningful, with a median duration of response of 35 weeks, and were associated with QoL improvements and corticosteroid dose re- 
ductions. Corticosteroid treatment was discontinued in $19 \%$ of patients ${ }^{144}$. The FFS rate was $76 \%$ and $47 \%$ at 6 and 12 months, respectively. The 2-year OS rate was $82 \%{ }^{144}$. Belumosudil was well-tolerated, with low rates of cytopenia. There were no unexpected adverse events and no apparent increased risk of infection, including CMV infection and reactivation ${ }^{144}$. Another phase II, randomized, multicenter registration study, published in the same year, evaluated belumosudil $200 \mathrm{mg}$ once daily and $200 \mathrm{mg}$ twice daily in 66 patients in each group with cGVHD who had received 2 to 5 prior lines of therapy ${ }^{145}$. Overall, median follow-up was 14 months. The best ORR of belumosudil $200 \mathrm{mg}$ once daily and $200 \mathrm{mg}$ twice daily was $74 \%$ and $77 \%$, respectively, with high response rates observed in all subgroups. All affected organs demonstrated complete responses, with a median duration of response of 54 weeks $^{145}$. Adverse events were consistent with those expected in patients with cGVHD receiving corticosteroids and other immunosuppressants ${ }^{145}$. Therefore, selective ROCK2 inhibition with belumosudil was found to be a promising therapy for refractory CGVHD, with a high ORR and OS rate, limited toxicity, and improvement in QoL, by allowing for steroid dose reduction in these patients ${ }^{144,145}$. Belumosudil was thus recently approved by the FDA for the treatment of CGVHD in adult and pediatric patients aged 12 years or older after failure of at least two prior lines of systemic therapy.

\section{OTHER DRUGS}

- Baracitinib: this is an inhibitor of Janus kinase 1 and 2 (JAK1/JAK2) which was shown to inhibit both the IFNGR and IL-6 receptor (IL6R), resulting in elimination of GVHD in a fully MHC-mismatched allo-HSCT model ${ }^{146}$. Baracitinib can also expand Tregs, by preserving JAK3-STAT5 signaling (thus providing a potential preventive role), and downregulate CXCR3 and Th1 and Th2 cells, while preserving allogeneic APC-stimulated T-cell proliferation ${ }^{146}$. Moreover, baracitinib may also be of benefit in the treatment of established GVHD by promoting intestinal tissue repair via epidermal growth factor receptor (EGFR) effects $^{147}$. Nonetheless, thus far, it has not been approved for the management of GVHD, and further studies are pending.

- Pomalidomide: thalidomide is active in mouse models of cGVHD and has been tested for the prevention and therapy of CGVHD in humans ${ }^{148}$. However, doses expected to be effective were poorly tolerated because of somnolence, neuropathy, and constipation. Pomalidomide is a new immune-modulating drug, with a 4000 -fold greater inhibition of TNFa relative to thalidomide, and is well tolerated, without the adverse effects commonly seen with the latter $^{149}$. Several features of pomalidomide suggest it may be useful in treating $\mathrm{CGVHD}^{149}$. In a phase II, open label, randomized study, patients with moderate/severe unresponsive or progressive CGVHD exhibited an ORR of $47 \%$ at 6 months, with a greater response rate in joint/fascia, followed by skin, GVHD ${ }^{149}$. Further studies may help elucidate its potential role in this setting.

\section{ORGAN-SPECIFIC MANAGEMENT AS AN ADJUVANT THERAPY FOR CGVHD}

Specific treatment and supportive care measures directed at individual target organs, such as the skin, genitalia, eyes, and mouth, have been thoroughly addressed in a previous issue of this journal, within the Consensus Guidelines for hematopoietic stem cell transplantation from the Brazilian Society for Blood and Marrow Transplantation and Cellular Therapy SBTMO, which we kindly encourage the reader to access for a deeper look into this matter ${ }^{150}$.

3. Jagasia MH, Greinix HT, Arora M, Williams KM, Wolff D, Cowen EW, et al. National Institutes of Health Consensus Development Project on Criteria for Clinical Trials in Chronic Graft-versusHost Disease: I. The 2014 Diagnosis and Staging Working Group report. Biol Blood Marrow Transplant. 2015 Mar;21(3):389-401.

4. Gale RP, Bortin MM, van Bekkum DW, Biggs JC, Dicke KA, Gluckman E, et al. Risk factors for acute graft-versus-host disease. Br J Haematol. 1987 Dec;67(4):397-406. 
5. Hahn T, McCarthy PL Jr, Zhang MJ, Wang D, Arora $M$, Frangoul $\mathrm{H}$, et al. Risk factors for acute graft-versus-host disease after human leukocyte antigen-identical sibling transplants for adults with leukemia. J Clin Oncol. 2008 Dec 10;26(35):5728-34.

6. Flowers ME, Inamoto Y, Carpenter PA, Lee SJ, Kiem $\mathrm{HP}$, Petersdorf EW, et al. Comparative analysis of risk factors for acute graft-versus-host disease and for chronic graft-versus-host disease according to National Institutes of Health consensus criteria. Blood. 2011 Mar 17;117(11):3214-9.

7. Zeiser R, Blazar BR. Acute Graft-versus-Host Disease - Biologic Process, Prevention, and Therapy. N Engl J Med. 2017 Nov 30;377(22):2167-2179.

8. Luft T, Benner A, Jodele S, Dandoy CE, Storb R, Gooley T, et al. EASIX in patients with acute graftversus-host disease: a retrospective cohort analysis. Lancet Haematol. 2017 Sep;4(9):e414-e423.

9. Ferrara JL, Levine JE, Reddy P, Holler E. Graftversus-host disease. Lancet. 2009 May 2;373(9674):1550-61.

10. Melín-Aldana H, Thormann K, Duerst R, Kletzel $M$, Jacobsohn DA. Hepatitic pattern of graft versus host disease in children. Pediatr Blood Cancer. 2007 Oct 15;49(5):727-30.

11. Carpenter PA, Macmillan ML. Management of acute graft-versus-host disease in children. Pediatr Clin North Am. 2010 Feb;57(1):273-95.

12. Ross WA, Ghosh S, Dekovich AA, Liu S, Ayers GD, Cleary KR, et al. Endoscopic biopsy diagnosis of acute gastrointestinal graft-versus-host disease: rectosigmoid biopsies are more sensitive than upper gastrointestinal biopsies. Am J Gastroenterol. 2008 Apr;103(4):982-9.

13. Rowlings PA, Przepiorka D, Klein JP, Gale RP, Passweg JR, Henslee-Downey PJ, et al. IBMTR Severity Index for grading acute graft-versus-host disease: retrospective comparison with Glucksberg grade. Br J Haematol. 1997 Jun;97(4):85564.

14. Cahn JY, Klein JP, Lee SJ, Milpied N, Blaise D, Antin $\mathrm{JH}$, et al. Prospective evaluation of 2 acute graft-versus-host (GVHD) grading systems: a joint Société Française de Greffe de Moëlle et Thérapie Cellulaire (SFGM-TC), Dana Farber Cancer Institute (DFCl), and International Bone Marrow Transplant Registry (IBMTR) prospective study. Blood. 2005 Aug 15;106(4):1495-500.
15. Przepiorka $D$, Weisdorf $D$, Martin $P$, Klingemann HG, Beatty P, Hows J, et al. 1994 Consensus Conference on Acute GVHD Grading. Bone Marrow Transplant. 1995 Jun;15(6):825-8.

16. Harris AC, Young R, Devine S, Hogan WJ, Ayuk $F$, Bunworasate $U$, et al. International, Multicenter Standardization of Acute Graft-versusHost Disease Clinical Data Collection: A Report from the Mount Sinai Acute GVHD International Consortium. Biol Blood Marrow Transplant. 2016 Jan;22(1):4-10.

17. Gatza E, Reddy P, Choi SW. Prevention and Treatment of Acute Graft-versus-Host Disease in Children, Adolescents, and Young Adults. Biol Blood Marrow Transplant. 2020 May;26(5):e101-e112.

18. Kennedy-Nasser AA, Ku S, Castillo-Caro P, Hazrat Y, Wu MF, Liu H, et al. Ultra low-dose IL-2 for GVHD prophylaxis after allogeneic hematopoietic stem cell transplantation mediates expansion of regulatory $T$ cells without diminishing antiviral and antileukemic activity. Clin Cancer Res. 2014 Apr 15;20(8):2215-25.

19. Pulsipher MA, Langholz B, Wall DA, Schultz KR, Bunin N, Carroll WL, et al. The addition of sirolimus to tacrolimus/methotrexate GVHD prophylaxis in children with ALL: a phase 3 Children's Oncology Group/Pediatric Blood and Marrow Transplant Consortium trial. Blood. 2014 Mar 27;123(13):2017-25.

20. Törlén J, Ringdén $O$, Garming-Legert $K$, Ljungman $\mathrm{P}$, Winiarski J, Remes $\mathrm{K}$, et al. A prospective randomized trial comparing cyclosporine/ methotrexate and tacrolimus/sirolimus as graftversus-host disease prophylaxis after allogeneic hematopoietic stem cell transplantation. Haematologica. 2016 Nov;101(11):1417-1425.

21. Törlén J, Gaballa $A$, Remberger $M$, Mörk $L M$, Sundberg B, Mattsson J, Uhlin M. Effect of Graftversus-Host Disease Prophylaxis Regimens on $\mathrm{T}$ and $\mathrm{B}$ Cell Reconstitution after Allogeneic Hematopoietic Stem Cell Transplantation. Biol Blood Marrow Transplant. 2019 Jun;25(6):12601268.

22. Khandelwal P, FukudaT, Mizuno K, Teusink-Cross A, Mehta PA, Marsh RA, et al A Pharmacokinetic and Pharmacodynamic Study of Maraviroc as Acute Graft-versus-Host Disease Prophylaxis in Pediatric Allogeneic Stem Cell Transplant Recipients with Nonmalignant Diagnoses. Biol Blood Marrow Transplant. 2016 Oct;22(10):1829-1835. 
23. Windreich RM, Goyal RK, Joshi R, Kenkre TS, Howrie D, Venkataramanan R. A Pilot Study of Continuous Infusion of Mycophenolate Mofetil for Prophylaxis of Graft-versus-Host-Disease in Pediatric Patients. Biol Blood Marrow Transplant. 2016 Apr;22(4):682-689.

24. Admiraal R, van Kesteren C, Jol-van der Zijde $\mathrm{CM}$, Lankester AC, Bierings MB, Egberts TC, et al. Association between anti-thymocyte globulin exposure and CD4+ immune reconstitution in paediatric haemopoietic cell transplantation: a multicentre, retrospective pharmacodynamic cohort analysis. Lancet Haematol. 2015 May;2(5):e194-203.

25. Locatelli F, Bernardo ME, Bertaina A, Rognoni C, Comoli P, Rovelli A, et al. Efficacy of two different doses of rabbit anti-T-lymphocyte globulin to prevent graft-versus-host disease in children with haematological malignancies transplanted from an unrelated donor: a multicentre, randomised, open-label, phase 3 trial. Lancet Oncol. 2017 Aug;18(8):1126-1136.

26. Watkins B, Qayed M, McCracken C, Bratrude B, Betz K, Suessmuth Y, et al. Phase II Trial of Costimulation Blockade With Abatacept for Prevention of Acute GVHD. J Clin Oncol. 2021 Jun 10;39(17):1865-1877.

27. Gooptu M, Antin JH. GVHD Prophylaxis 2020. Front Immunol. 2021 Apr 7;12:605726.

28. Pérez-Martínez A, Ferreras C, Pascual A, Gonzalez-Vicent $M$, Alonso $L$, Badell I, et al. Haploidentical transplantation in high-risk pediatric leukemia: A retrospective comparative analysis on behalf of the Spanish working Group for bone marrow transplantation in children (GETMON) and the Spanish Grupo for hematopoietic transplantation (GETH). Am J Hematol. 2020 Jan;95(1):28-37.

29. Locatelli F, Merli P, Pagliara D, Li Pira G, Falco M, Pende $D$, et al. Outcome of children with acute leukemia given HLA-haploidentical HSCT after $a \beta$ T-cell and B-cell depletion. Blood. 2017 Aug 3;130(5):677-685.

30. Penack O, Marchetti M, Ruutu T, Aljurf $M$, Bacigalupo A, Bonifazi $F$, et al. Prophylaxis and management of graft versus host disease after stem-cell transplantation for haematological malignancies: updated consensus recommendations of the European Society for Blood and Marrow Transplantation. Lancet Haematol. 2020 Feb;7(2):e157-e167.
31. Weiss M, Steinbach D, Zintl F, Beck J, Gruhn B. Superior outcome using cyclosporin $A$ alone versus cyclosporin A plus methotrexate for post-transplant immunosuppression in children with acute leukemia undergoing sibling hematopoietic stem cell transplantation. J Cancer Res Clin Oncol. 2015 Jun;141(6):108994.

32. Bleyzac N, Cuzzubbo D, Rénard C, Garnier N, Dubois V, Domenech C, et al. Improved outcome of children transplanted for high-risk leukemia by using a new strategy of cyclosporine-based GVHD prophylaxis. Bone Marrow Transplant. 2016 May;51(5):698-704.

33. Qayed M, Wang T, Hemmer MT, Spellman S, Arora M, Couriel D, et al. Influence of Age on Acute and Chronic GVHD in Children Undergoing HLA-Identical Sibling Bone Marrow Transplantation for Acute Leukemia: Implications for Prophylaxis. Biol Blood Marrow Transplant. 2018 Mar;24(3):521-528.

34. Jacoby E, Chen A, Loeb DM, Gamper CJ, Zambidis E, Llosa NJ, et al. Single-Agent Post-Transplantation Cyclophosphamide as Graft-versusHost Disease Prophylaxis after Human Leukocyte Antigen-Matched Related Bone Marrow Transplantation for Pediatric and Young Adult Patients with Hematologic Malignancies. Biol Blood Marrow Transplant. 2016 Jan;22(1):112-8.

35. Klein OR, Buddenbaum J, Tucker N, Chen AR, Gamper CJ, Loeb D, et al. Nonmyeloablative Haploidentical Bone Marrow Transplantation with Post-Transplantation Cyclophosphamide for Pediatric and Young Adult Patients with High-Risk Hematologic Malignancies. Biol Blood Marrow Transplant. 2017 Feb;23(2):325-332.

36. Symons HJ, Cluster A, Caywood E, et al. Haploidentical BMT using fully myeloablative conditioning, T cell replete bone marrow grafts, and post-transplant cyclophosphamide (PT/Cy) has limited toxicity and promising efficacy in the first prospective multicenter trial for pediatric, adolescent, and young adult patients with high risk acute leukemias and myelodysplastic syndrome. Biol Blood Marrow Transplant 2019; 25(3): 589.

37. Bertaina A, Zecca M, Buldini B, Sacchi N, Algeri $M$, Saglio $F$, et al. Unrelated donor vs HLA-haploidentical $\alpha / \beta$ T-cell- and B-cell-depleted HSCT in children with acute leukemia. Blood. 2018 Dec 13;132(24):2594-2607. 
38. Shelikhova L, llushina M, Shekhovtsova Z, Shasheleva D, Khismatullina R, Kurnikova E, et al. a $\beta$ T Cell-Depleted Haploidentical Hematopoietic Stem Cell Transplantation without Antithymocyte Globulin in Children with Chemorefractory Acute Myelogenous Leukemia. Biol Blood Marrow Transplant. 2019 May;25(5):e179-e182.

39. Lawitschka A, Lucchini G, Strahm B, Dalle JH, Balduzzi A, Gibson B, et al. Pediatric acute graftversus-host disease prophylaxis and treatment: surveyed real-life approach reveals dissimilarities compared to published recommendations. Transpl Int. 2020 Jul;33(7):762-772.

40. Darrigo LG Jr, Colturato V, de Souza MP, Loth G, Calixto R, Seber A, et al. Allogeneic Bone Marrow Transplants for Pediatric Severe Aplastic Anemia: Real-world Data comparing Matched Related and Unrelated Donors in a Developing Country. Retrospective study on behalf of the Pediatric Hematopoietic Stem Cell Transplant Working Group of the Brazilian Bone Marrow Transplantation Society (SBTMO) and the Brazil-Seattle Consortium (Gedeco). Pediatr Transplant. 2019 Nov;23(7):e13552.

41. Tavares RCB, Bonfim CS, Seber A, Pereira Lermontov S, Coulturato V, Zecchin VG, et al. Hematopoietic cell transplantation in pediatric patients with acute leukemias or myelodysplastic syndrome using unrelated adult or umbilical cord blood donors in Brazil. Pediatr Transplant. 2020 Nov;24(7):e13789.

42. Fernandes JF, Nichele $S$, Arcuri LJ, Ribeiro L, Zamperlini-Netto G, Loth $G$, et al. Outcomes after Haploidentical Stem Cell Transplantation with Post-Transplantation Cyclophosphamide in Patients with Primary Immunodeficiency Diseases. Biol Blood Marrow Transplant. 2020 Oct;26(10):1923-1929.

43. Elmariah H, Fuchs EJ. Post-transplantation cyclophosphamide to facilitate HLA-haploidentical hematopoietic cell transplantation: Mechanisms and results. Semin Hematol. 2019 Jul;56(3):183-189.

44. Walker I, Panzarella T, Couban S, Couture F, Devins G, Elemary M, et al. Addition of anti-thymocyte globulin to standard graft-versus-host disease prophylaxis versus standard treatment alone in patients with haematological malignancies undergoing transplantation from unrelated donors: final analysis of a randomised, open-label, multicentre, phase 3 trial. Lancet Haematol. 2020 Feb;7(2):e100-e111.
45. Admiraal R, Boelens JJ. Anti-thymocyte globulin for GVHD: one dose does not fit all. Lancet Haematol. 2020 Jul;7(7):e505.

46. Srinagesh HK, Ferrara JLM. MAGIC biomarkers of acute graft-versus-host disease: Biology and clinical application. Best Pract Res Clin Haematol. 2019 Dec;32(4):101111.

47. Giaccone L, Faraci DG, Butera S, Lia G, Di Vito C, Gabrielli G,et al. Biomarkers for acute and chronic graft versus host disease: state of the art. Expert Rev Hematol. 2021 Jan;14(1):79-96.

48. Naeije L, Kariminia A, Abdossamadi S, Azadpour S, Subrt P, Kuzeljevic B, et al. Anti-Thymocyte Globulin Prophylaxis Induces a Decrease in Naive Th Cells to Inhibit the Onset of Chronic Graft-versus-Host Disease: Results from the Canadian Bone Marrow Transplant Group (CBMTG) 0801 Study. Biol Blood Marrow Transplant. 2020 Mar;26(3):438-444.

49. Cuvelier GDE, Nemecek ER, Wahlstrom JT, Kitko $C L$, Lewis VA, Schechter T, et al. Benefits and challenges with diagnosing chronic and late acute GVHD in children using the NIH consensus criteria. Blood. 2019 Jul 18;134(3):304-316.

50. Gassas A, Schechter T, Krueger J, Craig-Barnes $H$, Sung $L$, Ali $M$, et al. Serum Krebs Von Den Lungen- 6 as a Biomarker for Early Detection of Bronchiolitis Obliterans Syndrome in Children Undergoing Allogeneic Stem Cell Transplantation. Biol Blood Marrow Transplant. 2015 Aug;21(8):1524-8.

51. Schultz KR, Kariminia A, Ng B, Abdossamadi S, Lauener M, Nemecek ER, et al. Immune profile differences between chronic GVHD and late acute GVHD: results of the ABLE/PBMTC 1202 studies. Blood. 2020 Apr 9;135(15):1287-1298.

52. Cuvelier GDE, Li A, Drissler S, Kariminia A, Abdossamadi S, Rozmus J, Chanoine JP, et al. "Age Related Differences in the Biology of Chronic Graft-Versus-Host Disease After Hematopoietic Stem Cell Transplantation". Front Immunol. 2020 Oct 16;11:571884.

53. Schoemans HM, Lee SJ, Ferrara JL, Wolff $D$, Levine JE, Schultz KR, et al; EBMT (European Society for Blood and Marrow Transplantation) Transplant Complications Working Party and the "EBMT-NIH (National Institutes of Health)CIBMTR (Center for International Blood and Marrow Transplant Research) GvHD Task Force". EBMT-NIH-CIBMTR Task Force position state- 
ment on standardized terminology \& guidance for graft-versus-host disease assessment. Bone Marrow Transplant. 2018 Nov;53(11):1401-1415.

54. Martin PJ, Schoch G, Fisher L, Byers V, Appelbaum FR, McDonald GB, et al. A retrospective analysis of therapy for acute graft-versus-host disease: secondary treatment. Blood. $1991 \mathrm{Apr}$ 15;77(8):1821-8.

55. Van Lint MT, Uderzo C, Locasciulli A, Majolino I, Scimé R, Locatelli $F$, et al. Early treatment of acute graft-versus-host disease with high- or low-dose 6-methylprednisolone: a multicenter randomized trial from the Italian Group for Bone Marrow Transplantation. Blood. 1998 Oct 1;92(7):2288-93.

56. Mielcarek $M$, Storer BE, Boeckh M, Carpenter PA, McDonald GB, Deeg HJ, et al. Initial therapy of acute graft-versus-host disease with low-dose prednisone does not compromise patient outcomes. Blood. 2009 Mar 26;113(13):2888-94.

57. Mielcarek $M$, Furlong $T$, Storer $B E$, Green $M L$, McDonald GB, Carpenter PA, et al. Effectiveness and safety of lower dose prednisone for initial treatment of acute graft-versus-host disease: a randomized controlled trial. Haematologica. 2015 Jun;100(6):842-8.

58. McDonald GB, Bouvier M, Hockenbery DM, Stern JM, Gooley T, Farrand A, et al. Oral beclomethasone dipropionate for treatment of intestinal graft-versus-host disease: a randomized, controlled trial. Gastroenterology. 1998 Jul;115(1):28-35.

59. Hockenbery DM, Cruickshank S, Rodell TC, Gooley T, Schuening F, Rowley S, et al. A randomized, placebo-controlled trial of oral beclomethasone dipropionate as a prednisone-sparing therapy for gastrointestinal graft-versus-host disease. Blood. 2007 May 15;109(10):4557-63.

60. Hings IM, Filipovich AH, Miller WJ, Blazar BL, McGlave PB, Ramsay NK, et al. Prednisone therapy for acute graft-versus-host disease: short- versus long-term treatment. A prospective randomized trial. Transplantation. 1993 Sep;56(3):577-80.

61. Martin PJ, Rizzo JD, Wingard JR, Ballen K, Curtin PT, Cutler C, et al. First- and second-line systemic treatment of acute graft-versus-host disease: recommendations of the American Society of Blood and Marrow Transplantation. Biol Blood Marrow Transplant. 2012 Aug;18(8):1150-63.
62. Deeg HJ. How I treat refractory acute GVHD. Blood. 2007 May 15;109(10):4119-26.

63. Alousi AM, Weisdorf DJ, Logan BR, Bolaños-Meade J, Carter S, Difronzo N, et al. Etanercept, mycophenolate, denileukin, or pentostatin plus corticosteroids for acute graft-versus-host disease: a randomized phase 2 trial from the Blood and Marrow Transplant Clinical Trials Network. Blood. 2009 Jul 16;114(3):511-7.

64. Furlong T, Martin P, Flowers ME, Carnevale-Schianca $F$, Yatscoff R, Chauncey T, et al. Therapy with mycophenolate mofetil for refractory acute and chronic GVHD. Bone Marrow Transplant. 2009 Dec;44(11):739-48.

65. Krejci M, Doubek M, Buchler T, Brychtova Y, Vorlicek J, Mayer J. Mycophenolate mofetil for the treatment of acute and chronic steroid-refractory graft-versus-host disease. Ann Hematol. 2005 Oct;84(10):681-5.

66. Gorgun G, Miller KB, Foss FM. Immunologic mechanisms of extracorporeal photochemotherapy in chronic graft-versus-host disease. Blood. 2002 Aug 1;100(3):941-7.

67. Hart JW, Shiue LH, Shpall EJ, Alousi AM. Extracorporeal photopheresis in the treatment of graft-versus-host disease: evidence and opinion. Ther Adv Hematol. 2013 Oct;4(5):320-34.

68. Greinix HT, Knobler RM, Worel N, Schneider B, Schneeberger A, Hoecker $P$, et al. The effect of intensified extracorporeal photochemotherapy on long-term survival in patients with severe acute graft-versus-host disease. Haematologica. 2006 Mar;91(3):405-8.

69. Shapiro RM, Antin JH. Therapeutic options for steroid-refractory acute and chronic GVHD: an evolving landscape. Expert Rev Hematol. 2020 May;13(5):519-532.

70. Rafei H, Kharfan-Dabaja MA, Nishihori T. A Critical Appraisal of Extracorporeal Photopheresis as a Treatment Modality for Acute and Chronic Graft-Versus-Host Disease. Biomedicines. 2017 Oct 11;5(4):60.

71. Malagola M, Cancelli V, Skert C, Leali PF, Ferrari E, Tiburzi A, et al. Extracorporeal Photopheresis for Treatment of Acute and Chronic Graft Versus Host Disease: An Italian Multicentric Retrospective Analysis on 94 Patients on Behalf of the Gruppo Italiano Trapianto di Midollo Osseo. Transplantation. 2016 Dec;100(12):e147-e155. 
72. Jagasia M, Greinix H, Robin M, Das-Gupta E, Jacobs R, Savani BN, et al. Extracorporeal photopheresis versus anticytokine therapy as a second-line treatment for steroid-refractory acute GVHD: a multicenter comparative analysis. Biol Blood Marrow Transplant. 2013 Jul;19(7):112933.

73. Greinix HT, Volc-Platzer B, Kalhs P, Fischer G, Rosenmayr A, Keil F, et al. Extracorporeal photochemotherapy in the treatment of severe steroid-refractory acute graft-versus-host disease: a pilot study. Blood. 2000 Oct 1;96(7):2426-31.

74. Abu-Dalle I, ReljicT, NishihoriT, Antar A, Bazarbachi A, Djulbegovic B, et al. Extracorporeal photopheresis in steroid-refractory acute or chronic graft-versus-host disease: results of a systematic review of prospective studies. Biol Blood Marrow Transplant. 2014 Nov;20(11):1677-86.

75. Schneiderman J. Extracorporeal photopheresis: cellular therapy for the treatment of acute and chronic graft-versus-host disease. Hematology Am Soc Hematol Educ Program. 2017 Dec 8;2017(1):639-644.

76. MacMillan ML, Weisdorf DJ, Davies SM, DeFor TE, Burns LJ, Ramsay NK, et al. Early antithymocyte globulin therapy improves survival in patients with steroid-resistant acute graft-versus-host disease. Biol Blood Marrow Transplant. 2002;8(1):40-6.

77. Carpenter PA, Sanders JE. Steroid-refractory graft-vs.-host disease: past, present and future. Pediatr Transplant. 2003;7 Suppl 3:19-31.

78. Massenkeil G, Rackwitz S, Genvresse I, Rosen O, Dörken B, Arnold R. Basiliximab is well tolerated and effective in the treatment of steroid-refractory acute graft-versus-host disease after allogeneic stem cell transplantation. Bone Marrow Transplant. 2002 Dec;30(12):899-903.

79. Funke VA, de Medeiros CR, Setúbal DC, Ruiz J, Bitencourt MA, Bonfim CM, et al. Therapy for severe refractory acute graft-versus-host disease with basiliximab, a selective interleukin-2 receptor antagonist. Bone Marrow Transplant. 2006 May;37(10):961-5.

80. Couriel D, Saliba R, Hicks K, Ippoliti C, de Lima $M$, Hosing $C$, et al. Tumor necrosis factor-alpha blockade for the treatment of acute GVHD. Blood. 2004 Aug 1;104(3):649-54.

81. Gómez VE, García-Gutiérrez V, Corral LL, Cade- nas IG, Martínez AP, Malaver FJM, et al. Ruxolitinib in refractory acute and chronic graft-versus-host disease: a multicenter survey study. Bone Marrow Transplant. 2020 Mar;55(3):641-648.

82. Yang W, Zhu G, Qin M, Li Z, Wang B, Yang J, et al. The Effectiveness of Ruxolitinib for Acute/ Chronic Graft-versus-Host Disease in Children: A Retrospective Study. Drug Des Devel Ther. 2021 Feb 22;15:743-752.

83. Vicent MG, Molina B, Pablo JG, Castillo A, Díaz MA. Ruxolitinib treatment for steroid refractory acute and chronic graft vs host disease in children: Clinical and immunological results. Am J Hematol. 2019 Mar;94(3):319-326.

84. Schroeder MA, Choi J, Staser K, DiPersio JF. The Role of Janus Kinase Signaling in Graft-VersusHost Disease and Graft Versus Leukemia. Biol Blood Marrow Transplant. 2018 Jun;24(6):11251134.

85. Choi J, Cooper ML, Alahmari B, Ritchey J, Collins L, Holt M, DiPersio JF. Pharmacologic blockade of JAK1/JAK2 reduces GvHD and preserves the graft-versus-leukemia effect. PLoS One. 2014 Oct 7;9(10):e109799.

86. Jagasia M, Perales MA, Schroeder MA, Ali $H$, Shah NN, Chen YB, et al. Ruxolitinib for the treatment of steroid-refractory acute GVHD (REACH1): a multicenter, open-label phase 2 trial. Blood. 2020 May 14;135(20):1739-1749.

87. FDA. FDA approves ruxolitinib for acute graftversus-host disease. 2019 Available from: https://www.fda.gov/drugs/resources-information-approved-drugs/fda-approves-ruxolitinibacute-graft-versus-host-disease

88. Zeiser R, von Bubnoff N, Butler J, Mohty M, Niederwieser D, Or R, et al. Ruxolitinib for Glucocorticoid-Refractory Acute Graft-versus-Host Disease. N Engl J Med. 2020 May 7;382(19):18001810.

89. Uygun V, Karasu G, Daloğlu H, Öztürkmen S, Kılıç SÇ, Yalçın K, et al. Ruxolitinib salvage therapy is effective for steroid-refractory graft-versus-host disease in children: A single-center experience. Pediatr Blood Cancer. 2020 Apr;67(4):e28190.

90.MinistériodaSaúde. Relatóriode Recomendação [Internet]. Brasília; 2016. Avaiable from: http:// conitec.gov.br/images/Consultas/Relatorios/2016/PCDT_Imunossupressao_TransplanteMedulaOssea_CP2016.pdf 
91. Lee SJ, Vogelsang G, Flowers ME. Chronic graftversus-host disease. Biol Blood Marrow Transplant. 2003 Apr;9(4):215-33.

92. Lee SJ, Flowers ME. Recognizing and managing chronic graft-versus-host disease. Hematology Am Soc Hematol Educ Program. 2008:134-41.

93. Kuzmina Z, Eder S, Böhm A, Pernicka E, Vormittag L, Kalhs $\mathrm{P}$, et al. Significantly worse survival of patients with $\mathrm{NIH}$-defined chronic graft-versushost disease and thrombocytopenia or progressive onset type: results of a prospective study. Leukemia. 2012 Apr;26(4):746-56.

94. Arora M, Klein JP, Weisdorf DJ, Hassebroek A, Flowers ME, Cutler CS, et al. Chronic GVHD risk score: a Center for International Blood and Marrow Transplant Research analysis. Blood. 2011 Jun 16;117(24):6714-20.

95. Jacobsohn DA, Arora M, Klein JP, Hassebroek A, Flowers ME, Cutler CS, et al. Risk factors associated with increased nonrelapse mortality and with poor overall survival in children with chronic graft-versus-host disease. Blood. 2011 Oct 20;118(16):4472-9.

96. Stewart BL, Storer B, Storek J, Deeg HJ, Storb $R$, Hansen JA, et al. Duration of immunosuppressive treatment for chronic graft-versus-host disease. Blood. 2004 Dec 1;104(12):3501-6.

97. Wolff D, Bertz H, Greinix H, Lawitschka A, Halter J, Holler E. The treatment of chronic graft-versushost disease: consensus recommendations of experts from Germany, Austria, and Switzerland. Dtsch Arztebl Int. 2011 Oct;108(43):732-40.

98. Couriel D, Carpenter PA, Cutler C, Bolaños-Meade J, Treister NS, Gea-Banacloche J, et al. Ancillary therapy and supportive care of chronic graft-versus-host disease: national institutes of health consensus development project on criteria for clinical trials in chronic Graft-versus-host disease: V. Ancillary Therapy and Supportive Care Working Group Report. Biol Blood Marrow Transplant. 2006 Apr;12(4):375-96.

99. Martin PJ, Carpenter PA, Sanders JE, Flowers ME. Diagnosis and clinical management of chronic graft-versus-host disease. Int J Hematol. 2004 Apr;79(3):221-8.

100. Flowers ME, Martin PJ. How we treat chronic graft-versus-host disease. Blood. 2015 Jan 22;125(4):606-15.
101. Martin PJ, Storer BE, Rowley SD, Flowers ME, Lee SJ, Carpenter PA, et al. Evaluation of mycophenolate mofetil for initial treatment of chronic graft-versus-host disease. Blood. 2009 May 21;113(21):5074-82.

102. Bredeson C, Rumble RB, Varela NP, Kuruvilla J, Kouroukis CT; Stem Cell Transplant Steering Committee. Extracorporeal photopheresis in the management of graft-versus-host disease. Curr Oncol. 2014 Apr;21(2):e310-25.

103. Greinix HT, Socié $G$, Bacigalupo A, Holler $E$, Edinger MG, Apperley JF, et al. Assessing the potential role of photopheresis in hematopoietic stem cell transplant. Bone Marrow Transplant. 2006 Aug;38(4):265-73.

104. Tsirigotis $P$, Kaloyannidis $P$, Papalexandri A, Baltadakis I, Karakasis D, Batsis I, et al. Extracorporeal photopheresis in the treatment of chronic graftversus-host disease. The Hellenic experience: a study by the Hellenic association of hematology. Transfus Apher Sci. 2012 Apr;46(2):173-80.

105. Malik MI, Litzow M, Hogan W, Patnaik M, Mu$\operatorname{rad} \mathrm{MH}$, Prokop LJ, et al. Extracorporeal photopheresis for chronic graft-versus-host disease: a systematic review and meta-analysis. Blood Res. 2014 Jun;49(2):100-6.

106. Couriel DR, Hosing C, Saliba R, Shpall EJ, Anderlini $\mathrm{P}$, Rhodes $\mathrm{B}$, et al. Extracorporeal photochemotherapy for the treatment of steroid-resistant chronic GVHD. Blood. 2006 Apr 15;107(8):307480. .

107. Nygaard M, KarlsmarkT, Andersen NS, Schjødt $I M$, Petersen SL, Friis LS, et al. Longitudinal follow-up of response status and concomitant immunosuppression in patients treated with extracorporeal photopheresis for chronic graft versus host disease. Bone Marrow Transplant. 2019 Jan;54(1):35-43.

108. Dignan FL, Aguilar S, Scarisbrick JJ, Shaw BE, Potter MN, Cavenagh J, et al. Impact of extracorporeal photopheresis on skin scores and quality of life in patients with steroid-refractory chronic GVHD. Bone Marrow Transplant. 2014 May;49(5):704-8.

109. Knobler R, Arenberger $P$, Arun A, Assaf C, Bagot $M$, Berlin $G$, et al. European dermatology forum: Updated guidelines on the use of extracorporeal photopheresis 2020 - Part 2. J Eur Acad Dermatol Venereol. 2021 Jan;35(1):27-49. 
110. Winther-Jørgensen S, Nygaard M, Heilmann C, Ifversen M, Sørensen K, Müller K, et al. Feasibility of extracorporeal photopheresis in pediatric patients with graft-versus-host disease after hematopoietic stem cell transplantation. Pediatr Transplant. 2019 Jun;23(4):e13416.

111. Wolff $D$, Schleuning $M$, von Harsdorf $S$, Bacher U, Gerbitz A, Stadler M, et al. Consensus Conference on Clinical Practice in Chronic GVHD: Second-Line Treatment of Chronic Graft-versus-Host Disease. Biol Blood Marrow Transplant. 2011 Jan;17(1):1-17.

112. Jagasia M, Scheid C, Socié G, Ayuk FA, Tischer J, Donato $\mathrm{ML}$, et al. Randomized controlled study of ECP with methoxsalen as first-line treatment of patients with moderate to severe cGVHD. Blood Adv. 2019 Jul 23;3(14):2218-2229.

113. Jurado $M$, Vallejo $C$, Pérez-Simón JA, Brunet $S$, Ferra C, Balsalobre P, et al. Sirolimus as part of immunosuppressive therapy for refractory chronic graft-versus-host disease. Biol Blood Marrow Transplant. 2007 Jun;13(6):701-6.

114. Giaccone L, Martin P, Carpenter P, Moravec C, Hooper H, Funke VA, et al. Safety and potential efficacy of low-dose methotrexate for treatment of chronic graft-versus-host disease. Bone Marrow Transplant. 2005 Aug;36(4):337-41.

115. Inagaki J, Nagatoshi Y, Hatano M, Isomura N, Sakiyama M, Okamura J. Low-dose MTX for the treatment of acute and chronic graft-versushost disease in children. Bone Marrow Transplant. 2008 Mar;41(6):571-7.

116. de Lavallade $H$, Mohty $M$, Faucher $C$, Fürst $S$, El-Cheikh J, Blaise D. Low-dose methotrexate as salvage therapy for refractory graft-versus-host disease after reduced-intensity conditioning allogeneic stem cell transplantation. Haematologica. 2006 Oct;91(10):1438-40.

117. Kanamaru A, Takemoto $Y$, Kakishita E, Dohy H, Kodera Y, Moriyama Y, et al. FK506 treatment of graft-versus-host disease developing or exacerbating during prophylaxis and therapy with cyclosporin and/or other immunosuppressants. Japanese FK506 BMT Study Group. Bone Marrow Transplant. 1995 Jun;15(6):885-9.

118. Carnevale-Schianca F, Martin P, Sullivan K, Flowers M, Gooley T, Anasetti C, et al. Changing from cyclosporine to tacrolimus as salvage therapy for chronic graft-versus-host disease. Biol Blood Marrow Transplant. 2000;6(6):613-20.
119. Mookerjee B, Altomonte V, Vogelsang G. Salvage therapy for refractory chronic graft-versus-host disease with mycophenolate mofetil and tacrolimus. Bone Marrow Transplant. 1999 Sep;24(5):517-20.

120. Lee SJ, Vogelsang G, Gilman A, Weisdorf DJ, Pavletic $\mathrm{S}$, Antin JH, et al. A survey of diagnosis, management, and grading of chronic GVHD. Biol Blood Marrow Transplant. 2002;8(1):32-9.

121. Lopez F, Parker $P$, Nademanee $A$, Rodriguez R, Al-Kadhimi Z, Bhatia R, et al. Efficacy of mycophenolate mofetil in the treatment of chronic graft-versus-host disease. Biol Blood Marrow Transplant. 2005 Apr;11(4):307-13.

122. Baudard $M$, Vincent $A$, Moreau $P$, Kergueris MF, Harousseau JL, Milpied N. Mycophenolate mofetil for the treatment of acute and chronic GVHD is effective and well tolerated but induces a high risk of infectious complications: a series of 21 BM or PBSC transplant patients. Bone Marrow Transplant. 2002 Sep;30(5):28795.

123. Cutler C, Miklos D, Kim HT, Treister N, Woo SB, Bienfang $D$, et al. Rituximab for steroid-refractory chronic graft-versus-host disease. Blood. 2006 Jul 15;108(2):756-62.

124. Mohty M, Marchetti N, El-Cheikh J, Faucher C, Fürst S, Blaise D. Rituximab as salvage therapy for refractory chronic GVHD. Bone Marrow Transplant. 2008 May;41(10):909-11.

125. Zaja F, Bacigalupo A, Patriarca F, Stanzani M, Van Lint MT, Filì C, et al. Treatment of refractory chronic GVHD with rituximab: a GITMO study. Bone Marrow Transplant. 2007 Aug;40(3):273-7.

126. Magro L, Catteau B, Coiteux V, Bruno B, Jouet JP, Yakoub-Agha I. Efficacy of imatinib mesylate in the treatment of refractory sclerodermatous chronic GVHD. Bone Marrow Transplant. 2008 Dec;42(11):757-60.

127. Moreno-Romero JA, Fernández-Avilés F, Carreras $E$, Rovira $M$, Martínez $C$, Mascaró JM Jr. Imatinib as a potential treatment for sclerodermatous chronic graft-vs-host disease. Arch Dermatol. 2008 Sep;144(9):1106-9.

128. Magro L, Mohty M, Catteau B, Coiteux V, Chevallier $\mathrm{P}$, Terriou $\mathrm{L}$, et al. Imatinib mesylate as salvage therapy for refractory sclerotic chronic graft-versus-host disease. Blood. 2009 Jul 16;114(3):719-22. 
129. Robin M, Guardiola P, Girinsky T, Hernandez G, Espérou $\mathrm{H}$, Ribaud $\mathrm{P}$, et al. Low-dose thoracoabdominal irradiation for the treatment of refractory chronic graft-versus-host disease. Transplantation. 2005 Sep 15;80(5):634-42.

130. Devillier R, Castagna L, Gonzague L, El-Cheikh J, Fürst S, Faucher C, et al. TLI in refractory chronic GVHD. Bone Marrow Transplant. 2013 Jun;48(6):854-8.

131. Ferreira AM, Szor RS, Molla VC, Seiwald MC, Moraes PA, Fonseca ARBM et al. Long-Term Follow-Up of Ruxolitinib in the Treatment of Steroid-Refractory Chronic Graft-versus-Host Disease. Transplantation and Cellular Therapy. 2021 Jun;27:777.e1-777e6.

132. Waller EK, Miklos D, Cutler C, Arora M, Jagasia $\mathrm{MH}$, Pusic l, et al. Ibrutinib for Chronic Graft-versus-Host Disease After Failure of Prior Therapy: 1-Year Update of a Phase 1b/2 Study. Biol Blood Marrow Transplant. 2019 Oct;25(10):2002-2007.

133. Miklos D, Cutler CS, Arora M, Waller EK, Jagasia $M$, Pusic I, et al. Ibrutinib for chronic graft-versushost disease after failure of prior therapy. Blood. 2017 Nov 23;130(21):2243-2250.

134. Jaglowski SM, Blazar BR. How ibrutinib, a B-cell malignancy drug, became an FDA-approved second-line therapy for steroid-resistant chronic GVHD. Blood Adv. 2018 Aug 14;2(15):2012-2019.

135. Teusink-Cross A, Davies SM, Grimley MS, Chandra S, Flannery A, Dandoy CE, et al. Ibrutinib for the treatment of chronic graft-vs-host disease in pediatric hematopoietic stem cell transplant patients: A single-center experience. Pediatr Transplant. 2020 May;24(3):e13692.

136. Nauta AJ, Fibbe WE. Immunomodulatory properties of mesenchymal stromal cells. Blood. 2007 Nov 15;110(10):3499-506.

137. Klyushnenkova E, Mosca JD, Zernetkina V, Majumdar MK, Beggs KJ, Simonetti DW, et al. T cell responses to allogeneic human mesenchymal stem cells: immunogenicity, tolerance, and suppression. J Biomed Sci. 2005;12(1):47-57.

138. Le BlancK, Tammik L, Sundberg B, Haynesworth $\mathrm{SE}$, Ringdén $\mathrm{O}$. Mesenchymal stem cells inhibit and stimulate mixed lymphocyte cultures and mitogenic responses independently of the major histocompatibility complex. Scand J Immunol. 2003 Jan;57(1):11-20.
139. Weng JY, Du X, Geng SX, Peng YW, Wang Z, Lu $Z S$, et al. Mesenchymal stem cell as salvage treatment for refractory chronic GVHD. Bone Marrow Transplant. 2010 Dec;45(12):1732-40.

140. Zhang LS, Liu QF, Huang K, Zhang Y, Fan ZP, Huang SL. [Mesenchymal stem cells for treatment of steroid-resistant chronic graft-versushost disease]. Zhonghua Nei Ke Za Zhi. 2009 Jul;48(7):542-6. [Chinese].

141. Weng J, He C, Lai P, Luo C, Guo R, Wu S, et al. Mesenchymal stromal cells treatment attenuates dry eye in patients with chronic graft-versushost disease. Mol Ther. 2012 Dec;20(12):2347-54.

142. Boberg E, von Bahr L, Afram G, Lindström $C$, Ljungman $\mathrm{P}$, Heldring $\mathrm{N}$, et al. Treatment of chronic GvHD with mesenchymal stromal cells induces durable responses: A phase II study. Stem Cells Transl Med. 2020 Oct;9(10):11901202.

143. Krasowska-Kwiecien A, Gozdzik J, Jarocha D, Wozniak M, Czogala W, Wiecha O, et al. Mesenchymal Stem Cells as a Salvage Treatment for Severe Refractory Graft-vs-Host Disease in Children After Bone Marrow Transplantation. Transplant Proc. 2019 Apr;51(3):880-889.

144. Jagasia M, Lazaryan A, Bachier CR, Salhotra $A$, Weisdorf DJ, Zoghi B, et al. ROCK2 Inhibition with Belumosudil (KD025) for the Treatment of Chronic Graft-Versus-Host Disease. J Clin Oncol. 2021 Jun 10;39(17):1888-1898.

145. Cutler CS, Lee SJ, Arai S, Rotta M, Zoghi B, Lazaryan A, et al. Belumosudil for Chronic Graftversus-Host Disease (cGVHD) After 2 or More Prior Lines of Therapy: The ROCKstar Study. Blood. 2021 Jul 15:blood.2021012021.

146. Choi J, Cooper ML, Staser K, Ashami K, Vij KR, Wang $B$, et al. Baracitinib-induced blockade of interferon gamma receptor and interleukin- 6 receptor for the preention and treatment of graft-versus-host disease. Leukemia, 2018; 32(11):22483-2494.

147. Kim, S, Ashami K, Lim S, Staser K, Vij K, Santhanam $S$, et al. Baracitinib prevents GVHD by increasesing Tregs via JAK3 and treats established GVHD by promoting intestinal tissue repair via EGFR. Leukemia, 2021. doi: 10.1038/s41375-02101360-9. Online ahead of print. 
148. Kulkarni S, Powles R, Sirohi B, Treleaven J, Saso $\mathrm{R}$, Horton $\mathrm{C}$, et al. Thalidomide after allogeneic haematopoietic stem cell transplantation: activity in chronic but not in acute graft-versushost disease. Bone Marrow Transplant 2003; 32: 165-170.

149. Pusic I, Rettig MP, DiPersio JF, Bauer S, McFarland K, Gale RP, et al. Phase-1/-2 study of poma- lidomide in chronic GVHD. Bone marrow Transplant. 2016; 51(4): 612-614.

150. Journal of Bone Marrow Transplantation and Cellular Therapy (JBMTCT) - Consensus Guidelines for hematopoietic stem cell transplantation from the Brazilian Society for Blood and Marrow Transplantation and Cellular Therapy - volume four n. 1, p.09-250, jan-mar 2021 - SBTMO 